\title{
La Conquista y la Colonia en el Códice Azcatitlan
}

María Castañeda de la Paz y Michel R. Oudijk

\section{OpenEdition}

\section{Journals}

Edición electrónica

URL: https://journals.openedition.org/jsa/12322

DOl: $10.4000 /$ jsa. 12322

ISSN: 1957-7842

Editor

Société des américanistes

\section{Edición impresa}

Fecha de publicación: 31 diciembre 2012

Paginación: 59-95

ISSN: 0037-9174

\section{Referencia electrónica}

María Castañeda de la Paz y Michel R. Oudijk, «La Conquista y la Colonia en el Códice Azcatitlan», Journal de la Société des américanistes [En línea], 98-2 | 2012, Publicado el 10 diciembre 2015 consultado el 02 septiembre 2022. URL: http://journals.openedition.org/jsa/12322 ; DOI: https:// doi.org/10.4000/jsa. 12322 


\title{
LA CONQUISTA Y LA COLONIA EN EL CÓDICE AZCATITLAN
}

\author{
María CASTAÑEDA DE LA PAZ y Michel R. OUDIJK *
}

El Códice Azcatitlan es un documento pictográfico del centro de México que contiene tres secciones históricas. Mientras las dos primeras tratan de la historia mexica antes de la llegada de los españoles y han sido objeto de relativamente muchos estudios, la última sección, que trata del periodo de conquista y colonización, no ha recibido la misma atención. No obstante, el registro de eventos por parte de los indígenas en este tiempo de profundos cambios nos indica que hubo el mismo interés tanto para los asuntos españoles como para los indígenas. No se percibe, además, ninguna inclinación por representar el sufrimiento al que está asociado este periodo. [Palabras claves: pictografía, Conquista, historia colonial, Nueva España.]

La Conquête et la Colonie dans le Codex Azcatitlan. Le Codex Azcatitlan est un document pictographique provenant du centre du Mexique et contenant trois sections historiques. Tandis que les deux premières traitent de l'histoire mexica avant l'arrivée des Espagnols et ont fait l'objet de plusieurs études, la dernière section, qui concerne la période de la Conquête et de la colonisation, n'a pas reçu la même attention. Cependant, l'enregistrement d'événements relatifs aux indigènes à cette époque de profonds changements nous indique que le même intérêt a été porté aux sujets espagnols et indigènes. Aucune inclination n'est, de plus, perceptible pour la représentation des souffrances qui caractérisent cette époque. [Mots-clés: pictographie, Conquête, histoire coloniale, Nouvelle Espagne.]

The Conquest and the Colony in the Codex Azcatitlan. The Codex Azcatitlan is a pictographic document from Central Mexico that contains three historical sections. While the first two, which concern the history of the Mexica before the arrival of the Spaniards, have been the object of relatively many studies, the last part, which deals with the conquest and colonization period, has not received similar attention. However, the register of events by indigenous people in this time of profound changes indicates that the same attention was given to Spanish matters as to those of themselves. Furthermore, no particular insistence can be perceived to represent the suffering which we

* Instituto de Investigaciones Antropológicas, Universidad Nacional Autónoma de México, Circuito Exterior s/n, Ciudad Universitaria, 04510 México, DF [mariacpz@unam.mx]. Instituto de Investigaciones Filológicas, Universidad Nacional Autónoma de México, Circuito Mario de la Cueva s/n, Ciudad Universitaria, 04510 México, DF [mroudyk@hotmail.com].

Journal de la Société des Américanistes, 2012, 98-2, pp. 59-95. C Société des Américanistes. 
associate today with this period. [Key words: pictography, Conquest, colonial history, New Spain.]

El Códice Azcatitlan es un documento del centro de México, del segundo tercio del siglo XVII. Encuadernado a la manera europea, su contenido está dividido en tres secciones, pintadas a color. La primera sección trata del origen y la historia de los mexicas, desde su vida en Aztlan hasta la fundación de Tenochtitlan y Tlatelolco, narrada en forma de anales (ff. 1r-13r); la segunda registra el gobierno de los señores tenochcas y tlatelolcas, con sus respectivas conquistas a modo de relato histórico (ff. 13v-22r), mientras que la tercera sección vuelve al formato de anales para narrar la llegada de los españoles y los primeros años de la vida colonial (ff. 22v-25v). Actualmente, el documento se encuentra en la Biblioteca Nacional de Francia bajo la catalogación BnF 59-64.

Los anales forman un grupo de textos históricos muy típico y reconocible por su estructura y organización (Lockhart 1992, pp. 376-392; Boone 2000, pp. 6570). Representan el paso del tiempo a través de una secuencia de años con eventos asociados al año en que sucedieron. Existen anales pictográficos, alfabéticos y mixtos. La mayoría de estos textos provienen del centro de México y están relacionados con pueblos nahuas, aunque existen excepciones como los Códices Azoyú 1 y 2 que tratan del señorío de Tlapa en Guerrero ${ }^{1}$ y el Códice de Huichapan que es otomí. Aunque solamente han sobrevivido ejemplares coloniales, los anales son probablemente de tradición prehispánica. De hecho, varios de los textos comienzan su historia antes de la Conquista y siguen hasta el siglo XVII.

Ahora bien, como fuentes provenientes de pueblos o ciudades específicas, los eventos plasmados en los anales pueden ser de naturaleza local, como por ejemplo la muerte de un gobernante o la visita de un juez, aunque también pueden incorporar asuntos de carácter regional como terremotos, sequías o la llegada de los virreyes. No obstante, sea cual sea la naturaleza de los eventos registrados, el enfoque del documento siempre está en la localidad o el efecto que el evento tiene sobre ésta. Al analizar el Códice Azcatitlan se puede entonces esperar que algunas escenas se logren encontrar en muchas otras fuentes, incluso de otras regiones, mientras que otras serán más difíciles de interpretar por estar relacionadas con eventos muy locales.

Considerando lo mencionado, es importante notar que el contenido del Códice Azcatitlan refiere plenamente a la ciudad de México, incluyendo los altepeme (pueblos) de Tenochtitlan y Tlatelolco. Esta observación es relevante porque condiciona la interpretación del texto pictográfico: siendo un documento de la ciudad de México, no se esperaría la representación de eventos o de personajes que no formaran parte de la historia de la ciudad, a menos que fuera por una razón muy específica. O sea, el pintor no daría protagonismo a un evento o persona si no fuera para glorificar su localidad o para explicar un 
acontecimiento que considerara notable. Entonces tenemos que tomar en cuenta este aspecto, que es la línea que nos guía en la interpretación. Es decir, que si uno quiere identificar el significado de una escena, en este caso en el Códice Azcatitlan, primero tendrá que optar por un evento en la ciudad de México; después por uno regional, pero con relevancia para la ciudad; y excepcionalmente por otro significado, pero con una elaborada explicación en cuanto al porqué la escena fue incluida en el códice.

\section{Estudios PREVIOS}

Barlow (1949) fue el primer investigador en publicar un comentario integral sobre el Códice Azcatitlan, acompañado de una edición facsimilar. Su trabajo consistió en relacionar básicamente el contenido del Códice Azcatitlan con el de otros documentos históricos de la peregrinación de los mexica, hasta la llegada y conquista de los españoles. En 1995, Graulich publicó el comentario de Barlow, al que añadió sus propias anotaciones mediante notas a pie de página, e hizo una nueva introducción al documento. Se trató de una publicación bilingüe (en francés y español), acompañada de un facsímil de tan alta calidad que apenas se diferencia del documento original.

Más recientemente, Boone (2000) y Navarrete (2000) han publicado sendos textos que tratan sobre la estructura del relato histórico y la organización del tiempo y el espacio en el manuscrito. En una serie de artículos, Castañeda de la Paz (1997, 1999, 2005, 2009a, 2009b, s. d.) ha sugerido que el códice tiene una estrecha relación con Tlatelolco y que se elaboró en la segunda mitad del siglo XVII. Además de esto, la autora 1) demuestra la relación que existe entre el Códice Azcatitlan y el corpus documental conocido como Grupo Ixhuatepec (2004, Códice Cozcatzin, Códice Ixhuatepec y Códice Chavero entre otros), 2) revela a través del análisis de las glosas de los códices Azcatitlan, Cozcatzin e Ixhuatepec que el amanuense de las tres fuentes fue el mismo y 3 ) retoma el tema de los pintores de los documentos, pues aunque fueron distintos, tuvieron al alcance las mismas fuentes o modelos iconográficos, algo que ya había observado Barlow (1949, p. 103) y más recientemente Boone (2000, pp. 214-215). Prueba de este último aspecto es que en varias ocasiones los pintores utilizaron los mismos topónimos, glifos onomásticos u otros detalles iconográficos, los cuales también tuvo presente el pintor del Códice Techialoyan García Granados, éste de fecha más tardía (primera mitad del siglo XVIII).

Finalmente, Navarrete (2004) confirma la relación entre el Códice Azcatitlan y Tlatelolco y demuestra, a través de un análisis de estilo, la influencia europea presente en el manuscrito. 


\section{El MÉtodo APLICADo}

La parte del Códice Azcatitlan que se analizará en este trabajo es la correspondiente al periodo colonial y, por tanto, a la tercera sección del documento (ff. $22 \mathrm{v}-25 \mathrm{v}$ ). Aunque comentada por Barlow y Graulich, es claro que ambos investigadores estaban menos interesados en esta parte del códice. Y es que si los folios sobre el tiempo prehispánico recibieron un promedio de dos a tres páginas de comentario, los folios del periodo colonial, por lo general, sólo recibieron una. En este sentido, llama la atención que Graulich no añadiera ninguna nota a los comentarios de Barlow en dos de los folios del periodo colonial (ff. 23v y 24r), algo que no había pasado con ninguno de los folios anteriores.

Esta sección se organiza de manera cronológica, lo que implica un desarrollo a través del tiempo, en este caso, de un cierto momento histórico hasta otro más reciente. Metodológicamente, esto tiene como consecuencia que, aunque no hay indicadores de tiempo en esa parte del códice, los eventos representados muestren una organización secuencial temporal de lo más antiguo a lo más reciente como veremos más adelante. En cuanto a su estructura, hay tres grandes escenas que cubren dos páginas cada una: 1) la llegada de los españoles a Tenochtitlan y la recepción por parte de Moctezuma Xocoyotzin en 1519 que cubre el folio 22v y el lado recto de un folio faltante; 2) la masacre de la fiesta de Toxcatl que está plasmada en el lado verso del folio faltante y el folio 23r; 3) y la conquista de la ciudad de México en los folios 23v y 24. Después, la organización cambia y se dibujan varias escenas en una sóla página, representando cada una de ellas una década. Tenemos así que el folio $24 \mathrm{v}$ abarca los años veinte del siglo XVI, el lado recto y verso de un folio faltante debería haber registrado los años 1530 y 1540, respectivamente, mientras que el folio $25 \mathrm{r}$ contiene la década de los 1550 y el $25 \mathrm{v}$ la de los años 1560 .

Ahora bien, como con cualquier estudio sobre iconografía y pictografía mesoamericana, el presente trabajo está basado en la comparación de varios documentos históricos, pictográficos y alfabéticos, relacionados con el mismo tema y espacio de tiempo. El método aquí aplicado es el de la etno-iconología (Loo 1986; Jansen 1986, 1988; Oudijk 2000, 2008). Un acercamiento metodológico que primeramente identifica los elementos pictográficos mínimos a través de una comparación con otros documentos pictográficos. A continuación aúna estos elementos mínimos en unidades temáticas mediante las cuales, y a través de algunas analogías, se puede proponer una lectura interpretativa. La interpretación, basada en analogías, se justifica aplicando siempre unidades temáticas, donde los elementos mínimos se hallan enlazados por relaciones significativas que se encuentran, al menos, en dos contextos diferentes. En este caso, en fuentes históricas.

Para la comparación de las escenas del Códice Azcatitlan existe un considerable corpus de documentos. Sólo tres de éstos son enteramente 
pictográficos: el Códice en Cruz (1981), el Códice Mexicanus (1952) y el Códice de Tlatelolco (1980, 1994). Chimalpain (2003), por su parte, nos ha legado amplios anales escritos que versan sobre el periodo en cuestión, mientras que Tezozomoc (1992) lo hizo en menor medida por estar más interesado en los linajes tenochcas. Ahora bien, la gran mayoría de los anales son mixtos: el Códice Vaticano $A$ (1996), el Códice Telleriano-Remensis (1995), el Códice Aubin (1963, 1981) y los Manuscritos Mexicains núms. 40 y 217 (1981). Obviamente, también existen crónicas, como las de Sahagún (2000) y Durán (1995), las cuales proporcionan importante información histórica que nos hacen entender lo representado en la tercera sección del Códice Azcatitlan.

\section{LA Conquista (ff. 22v-24r)}

El Códice Azcatitlan constaba originalmente de 28 folios por lo menos, aunque debido a que algunas escenas carecen de su contraparte se puede afirmar que en algún momento se perdieron tres de esos folios (Graulich 1995, p. 16). La mayoría de las pérdidas se concentran en la sección de la Conquista y la Colonia, de ahí que la lectura en algunas ocasiones se dificulte, como se le irá explicando al lector a lo largo de nuestro análisis. Respecto a la foliación, se seguirá la del documento original, señalada en rojo en la esquina superior derecha del lado recto de cada folio. Hemos considerado que es lo más justificable metodológicamente ${ }^{2}$.

\section{Folio 22v: la llegada de los españoles a Tenochtitlan (Figura 1)}

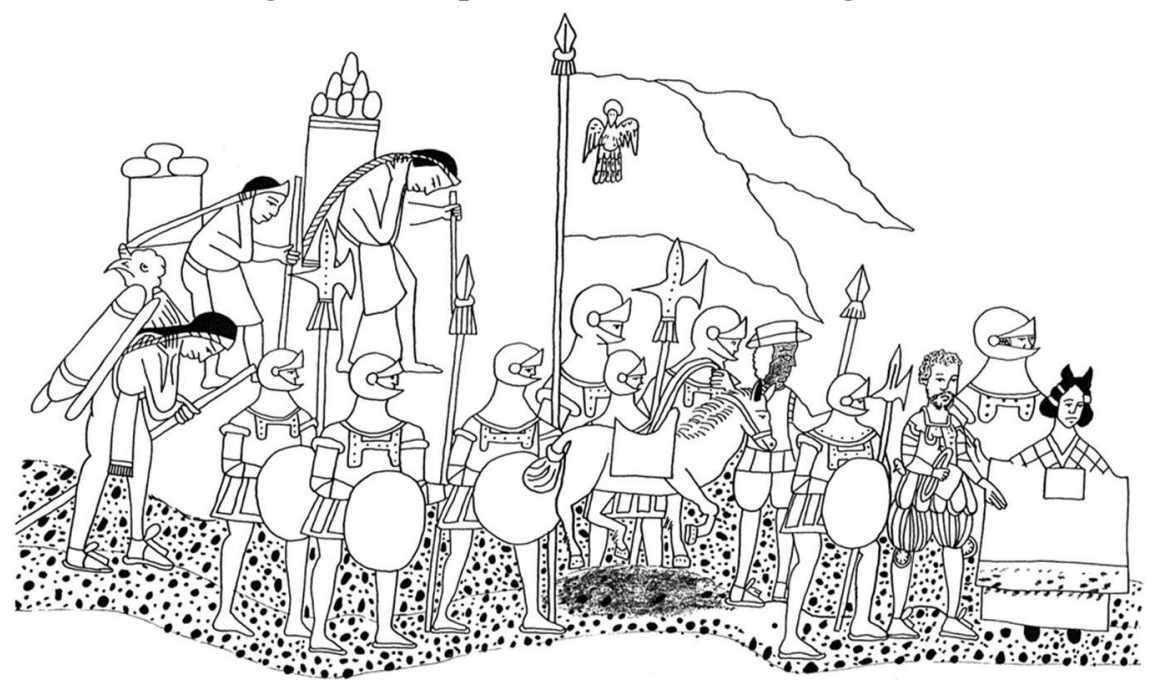

FIG. 1 - Llegada de los españoles (folio 22v del Códice Azcatitlan). 
En la imagen vemos a un grupo de personajes encabezados por doña Marina y Hernán Cortés, ambos ricamente ataviados. Ella viste un huipil y él un jubón, chaqueta y sombrero en mano. Tras ellos figura un personaje de piel oscura que también está vestido a la manera europea y lleva un caballo cogido por las riendas, el cual se dibujó en una escala mucho menor. Detrás, los soldados españoles con armadura, casco, escudo y lanza, cargando uno de ellos el estandarte del Espíritu Santo. Al final aparece un grupo de tamemes (cargadores) llevando en sus espaldas los huacales llenos de comida.

Todos avanzan por un camino pedregoso, aunque parecen detenerse al haber llegado a un punto de encuentro. A pesar de que la otra parte de la escena está perdida, el paralelo con otras fuentes pictográficas y alfabéticas de esta temática permite afirmar que la escena representa la llegada de Cortés a las puertas de Tenochtitlan. Graulich (1995, p. 136, nota 91) señalaba que doña Marina aparecía representada en actitud de intérprete, por lo que en el folio perdido debía hallarse el personaje al que debía introducir y cuyas palabras debía traducir. O sea, el huey tlatoani Moctezuma Xocoyotzin, gobernante de Tenochtitlan en 1519.

La escena descrita es similar a la dibujada en el folio 26r del Códice Florentino (1979, libro 12, cap. 16, f. 26r), donde doña Marina ocupa un puesto central en la imagen como comunicadora, con volutas que salen de los conquistadores hacia ella y de ella hacia los tlatoque (señores gobernantes). Otra imagen similar sería la lámina 58 de la obra de Durán (1995, vol. I). Aunque doña Marina y los tamemes no están dibujados en ella, sí se tuvo cuidado en pintar a Cortés con el sombrero en la mano, acompañado de su esclavo negro que le sujeta el caballo y detrás, al grupo de conquistadores con sus armaduras y lanzas ${ }^{3}$. Frente a él se dispuso a Moctezuma y un grupo de nobles indígenas.

Al respecto, Durán explicaba que después de que Moctezuma le diera la bienvenida al conquistador, éste se sometió al servicio del rey de España. Cortés entonces le respondió « con mucha crianza y cortesía, quitando la gorra ó sombrero de la cabeza y baxándola, mostrando en ello reverencia y agradecimiento » (Durán 1995, vol. I, cap. 74, p. 612). Con esto se explica el detalle de hallarse Cortés con el sombrero en la mano. En cuanto al estandarte del Espíritu Santo, no es otra cosa que la representación de la llegada de la nueva religión traída por los españoles, de ahí que suela asociarse dicho estandarte a este tipo de escenas ${ }^{4}$.

Ya sólo resta decir que la presencia de los tamemes indígenas no es algo excepcional. Recientemente, se ha revalorizado el importante papel que éstos jugaron en las diversas campañas por toda Mesoamérica, pues cargaban la comida que luego las mujeres que iban con ellos se encargaban de preparar ${ }^{5}$.

Lamentablemente la escena está incompleta y desconocemos la manera en la que los pintores del Códice Azcatitlan hubieran representado a Moctezuma y todo su séquito. 


\section{Folio 23r: la matanza en la fiesta del Toxcatl (Figura 2)}

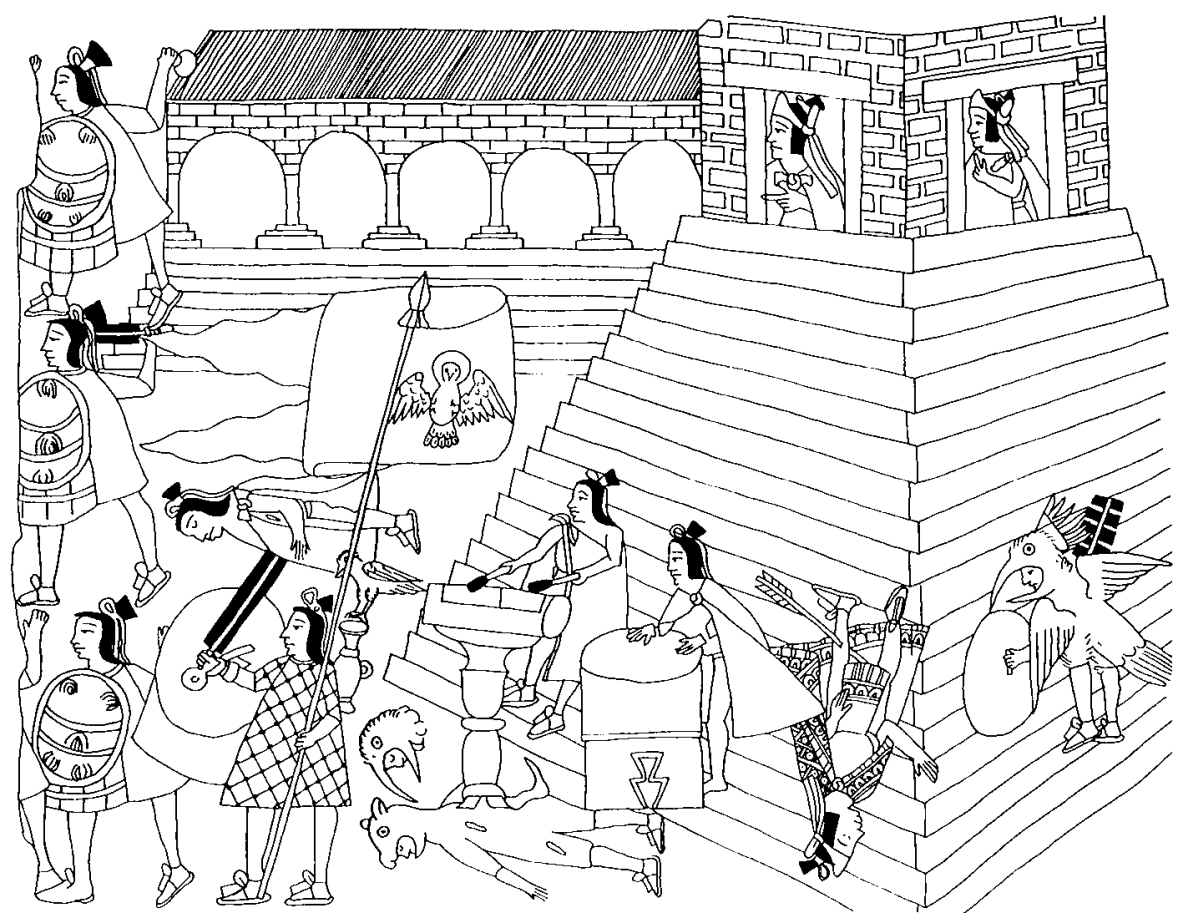

FIG. 2 - Fiesta del Toxcatl (folio 23r del Códice Azcatitlan).

La escena representa el recinto ceremonial de Tenochtitlan. Al fondo se dibujó un edificio porticado con escalinatas de acceso y en primer plano el Templo Mayor con una tridimensionalidad y perspectiva no del todo lograda. En su cima se representaron los dos adoratorios que estaban en la parte superior de la gran estructura que era el Templo Mayor. En el interior de cada uno se ve a un tlatoani, tal como indican las xiuhhuitzolli o diademas de turquesa que llevan ceñidas en sus cabezas. En las escalinatas yace otro tlatoani muerto (con ojos cerrados) por herida de flecha y quizás por descalabrarse en la caída. Junto a él aparece un guerrero con atuendo de colibrí, armado con escudo y macuahuitl.

A los pies del templo se dibujaron dos músicos con sendos tambores: un huehuetl y un teponaxtle. Frente a ellos algunos guerreros con el característico peinado del temillotl, en posición de ataque, portando escudos, macanas, y uno de ellos el estandarte del Espíritu Santo. En el suelo reposan algunos ya muertos, entre ellos un guerrero jaguar, aunque no se terminó de pintar su atavío con las 
manchas de este animal, como sucede con casi todas las vestimentas de los personajes de este folio ${ }^{6}$.

En frente de los guerreros indígenas debían estar los soldados españoles, pero debido a que la parte derecha de la escena anterior (folio 22v) se perdió, es por lo que al folio $23 \mathrm{r}$ le falta la parte izquierda de la escena, siendo ésta el reverso del folio perdido. Pero fue precisamente la falta de españoles en la escena lo que hizo dudar a Graulich (1995, p. 138, nota 92) de que el suceso aquí representado fuera el de la fiesta del Toxcatl, durante el cual se produjo una grave matanza. No obstante, el análisis comparativo con otras pictografías, así como la descripción que existe de los acontecimientos en varios textos alfabéticos, nos permiten afirmar que, efectivamente, se trata de este episodio.

Según varios relatos, la matanza de Toxcatl tuvo lugar en 1520, cuando Cortés se ausentó de Tenochtitlan en busca de Pánfilo de Narváez, dejando al conquistador Pedro de Alvarado a cargo de la ciudad ${ }^{7}$. Dicen las fuentes que en esos días los tenochcas pidieron permiso para celebrar su fiesta del toxcatl, aunque hay otras versiones que señalan que ésta se celebró a petición de los españoles ${ }^{8}$. En cualquier caso, la festividad fue permitida siempre y cuando no se portasen armas ni se realizasen sacrificios. Empero, hay quien dice que advertido por una posible conspiración, Alvarado dio orden de iniciar la matanza (López de Gómara, 1987, p. 230) ${ }^{9}$.

El acto debió ser de tal impacto que existen de él varios registros pictográficos. En el folio 42r del Códice Aubin se pintó, por ejemplo, el recinto ceremonial con el templo de Tlaloc y Huitzilopochtli, a cuyos pies sólo se dibujó al músico que tocaba el huehuetl, y en primer plano a un indígena y a un conquistador español, ambos armados. Otra representación es la del folio 89r del Códice Vaticano $A$ donde tan sólo se representó el Templo Mayor con un español que acaba de descuartizar un sacerdote. El folio $15 \mathrm{r}$ del Manuscrito Mexicain núm. $40^{10}$ plasmó asimismo el templo principal de la ciudad y, para evitar equívocos, en él se pintó el topónimo de Tenochtitlan. Se trata de una escena que va acompañada de conquistadores españoles frente a un grupo de guerreros indígenas, algunos ya descuartizados. Como en el Códice Azcatitlan, en la lámina 59 de Durán (1995, vol. I) también se pintó un recinto ceremonial porticado y en el centro el huehuetl, el teponaxtle, pero además se tuvo cuidado de dibujar las baquetas de los músicos, mostrando con ello la significación de estos instrumentos en la fiesta. Alrededor, conquistadores llevando a cabo la matanza en la que aparecen señores y tlatoque - algunos armados -, mutilados y decapitados. Sahagún (2000, libro XII, cap. 20) explica y representa figurativamente la presencia de tenochcas armados cuando dice que después de la masacre de la ciudad fueron llamados en armas. Por ello consideramos que las representaciones pictográficas en el Códice Aubin, Manuscrito Mexicain núm. 40, Durán y, por tanto, en el Códice Azcatitlan, pueden ser representaciones secuenciales que plasman en una escena varios eventos que ocurrieron seguidamente. 
Ahora bien, es elocuente que a través de la imagen o la palabra, casi todas las fuentes dieron cuenta del agravio que se le hizo a los que tocaban los instrumentos. Durán (1995, libro I, cap. 75, p. 620) dice que la orden fue matar primero a los que tocaban el tambor y luego a los que estaban alrededor, porque parecían ser los hombres más ilustres; el Códice Aubin (1963, p. 56) especifica que eran dos los que tañían los atabales, a los cuales fueron a golpear. Los Anales de Tlatelolco (2004, p. 103) precisaban que les golpearon en las manos y en la boca, y luego los mataron. Pero más impactante aún es leer en el folio $15 \mathrm{r}$ del Manuscrito Mexicain núm. 40, y también en la obra de Sahagún (2000, libro XII, cap. 20, p. 1194), cómo a éstos les cortaron las manos y se las hicieron pedazos:

\section{[...] nimā quimavitecque in tlatzotzona oalcocoton vumexti in imacpal çatepan} quiquechvitecque veca vetzito in iquech:

[...] They struck a drummer's arms; both of his hands were severed. Then they struck his neck; his head landed far away. (Lockhart 1993, p. 134)

Y es que así, mutilado, es como está dibujado el músico que toca el huehuetl en el Códice Azcatitlan ${ }^{11}$. En el folio 33r del Códice Florentino, libro 12, aunque la matanza se recogió en viñetas, en una de ellas se registró también al músico del huehuetl (un tlatoani) mutilado, con una de sus manos tirada en el suelo (Figura 3a). Similar es la escena del folio 15r del Manuscrito Mexicain núm. 40. A pesar de que allí no se pintó el tambor, puede verse que entre los indígenas descuartizados está la mano del músico con la baqueta todavía en su puño (Figura 3b). En base a todo este análisis, no tenemos entonces duda de que el folio 23r del Códice Azcatitlan, aunque no está completo, representa la matanza que se llevó a cabo durante la fiesta del Toxcatl en el recinto ceremonial de Tenochtitlan, la cual desencadenó la famosa Noche Triste.
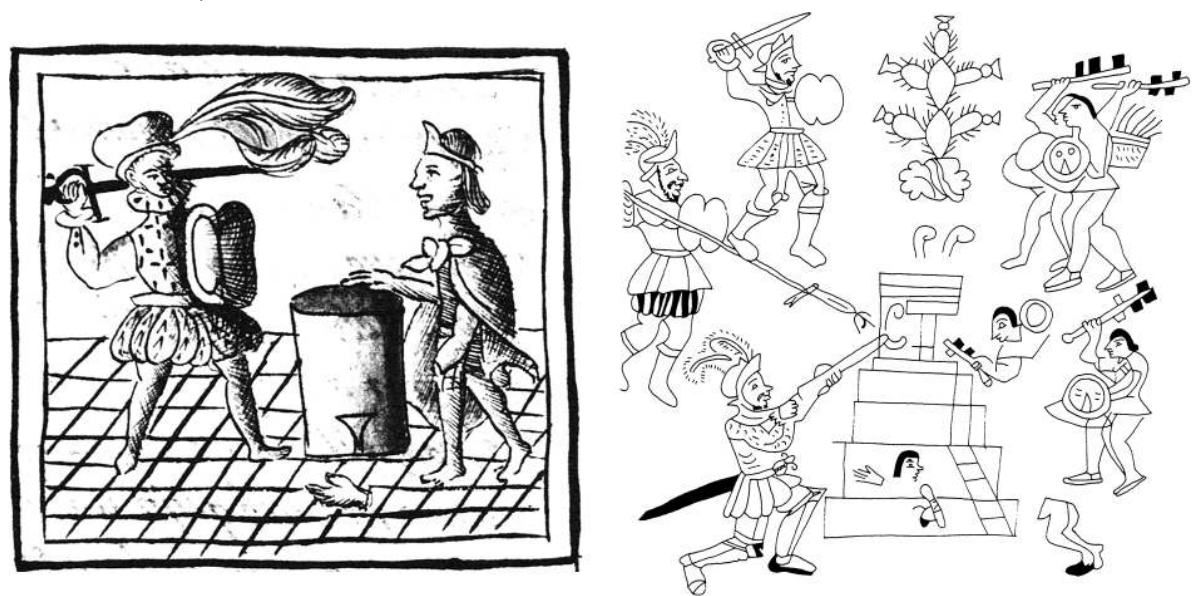

FIG. 3 - a) Detalle del Códice Florentino (libro 12, folio 33r). b) Detalle del Manuscrito Mexicain núm. 40 (folio 15r). 
Es interesante notar que aunque se trata de una fiesta mesoamericana, son los tenochcas los que llevan el estandarte del Espíritu Santo para que éste, supuestamente, los proteja de los españoles. Es decir, como si fueran ellos los que estuvieran luchando a favor del cristianismo. Si esto es así, el mensaje contenido en esta escena parece decir que los tenochcas ya estaban bautizados y, por tanto, eran cristianos. Asimismo, que la única razón por la que organizaron la fiesta en honor a Huitzilopochtli fue porque los españoles los invitaron a hacerlo, tal como confirman Sahagún (2000, libro XII, cap. 19, p. 1193) y Durán (1995, vol. I, cap. 75, p. 619). En base a ello, lo que el Códice Azcatitlan estaría enfatizando es el engaño español que dio como resultado la masacre de la fiesta de Toxcatl. O sea, estaríamos antes una escena que tiene la finalidad de expresar una queja histórica, a través de la cual los mexicas reclaman que, aunque ya vivían como cristianos, los españoles los castigaron utilizando el falso argumento de la idolatría.

\section{Folios 23v-24r: La toma de Tlatelolco y Tenochtitlan (Figura 4)}
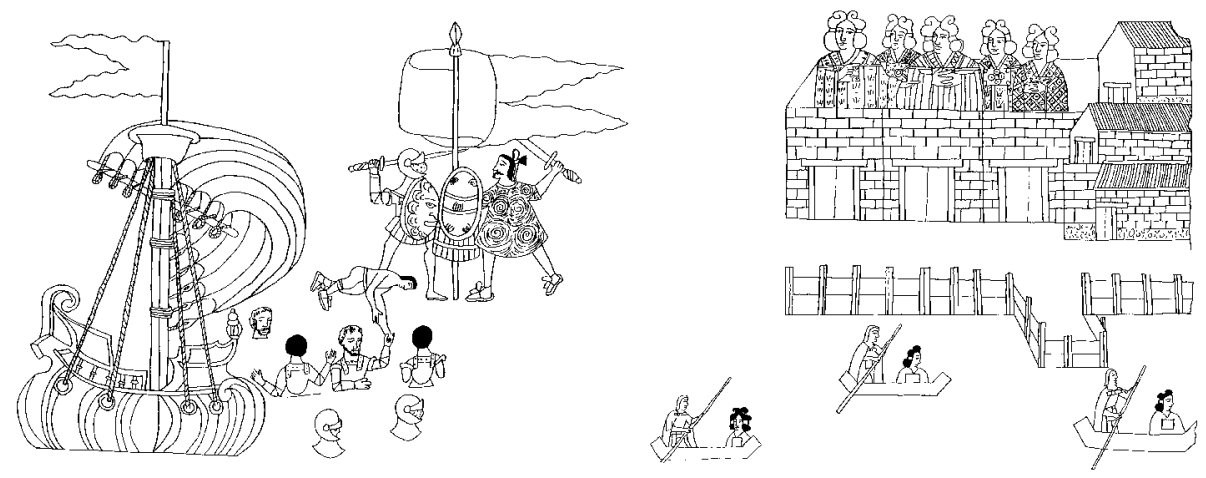

FIG. 4 - La toma de Tlatelolco y Tenochtitlan (folios 23v-24r del Códice Azcatitlan).

Barlow (1995, p. 140) dudaba si la presente escena era independiente de la que él terminó numerando como lámina XXVI (folio 24r), o si ambas escenas debían leerse como una sola. Desde luego, ambas se desarrollan en un ambiente acuático, aunque a nuestra manera de ver no era necesario colocar una hoja en blanco entre uno y otro folio como él hizo, creyendo que se había perdido el final de la escena del folio $23 \mathrm{v}$ y el principio de la del folio $24 \mathrm{r}$.

A la izquierda de la escena, y en un primer plano, tenemos un bergantín pintado con mucho detalle, mientras que en un segundo plano aparecen dos hombres con un estandarte por medio, que luchan cada uno con sus armas. 
El primero es un español, con armadura, espada y escudo, mientras que el segundo es un mexica, vestido con un ichcahuipil (traje de algodón) decorado con motivos acuosos ${ }^{12}$, cactles (sandalias), el peinado de temilotl, un chimalli (escudo) y una espada europea. Una atenta mirada al dibujo permite ver que es el guerrero indígena el que porta el estandarte, corroborando la lectura de la escena anterior (folio 23r). Entre ellos y el bergantín se dibujaron algunos conquistadores que parecen estar sumergidos en el agua, la cual no aparece dibujada. No obstante, el hecho de aparecer representados de medio cuerpo o sólo a través de su cabeza junto al bergantín, sugiere que están sumergidos en ésta. En folio $24 \mathrm{r}$ se pintaron varias edificaciones con algunas mujeres en sus azoteas. Delante de ellas hay una albarrada de madera y frente a ésta unos acalli (barcas) donde algunas mujeres son llevadas por sus remeros a algún lugar.

Barlow (1995, p. 140) se vio en la tesitura de determinar qué eventos se representaban en la primera parte del folio $23 \mathrm{v}$, pues vio que la presencia del bergantín podría hacer alusión al mar y, por tanto, a la llegada de Pánfilo de Narváez a la costa de Veracruz. No obstante, reconocía que la escena de batalla y la de los españoles metidos en las aguas apuntaban más bien al sitio de México, lo cual en nuestra opinión es precisamente lo que aquí se pintó. De esta manera, la imagen del bergantín no vendría más que a hacer alusión a aquellos que Cortés mandó construir en Texcoco, como asimismo registra la lámina 61 de la obra de Durán (1995, vol. I). Unos bergantines que después echó en el gran lago de Texcoco para ir a asediar a los mexicas, entrando a la par por Tlatelolco y Tenochtitlan. Así pues, mientras en el folio $23 \mathrm{v}$ se narraron los sucesos más importantes que tuvieron lugar en Tlatelolco, demostraremos aquí que en el folio $24 \mathrm{r}$ se narró cierto evento que tuvo lugar en Tenochtitlan ${ }^{13}$.

En cuanto a los episodios de guerra recogidos en Tlatelolco, éstos parecen enfocarse en las batallas de Alvarado y en la caída de Cortés a cierta acequia, en la que estuvo a punto de perecer, cuando ya había conquistado la parte de Tenochtitlan. Para lo primero nos basamos en la identificación que Barlow (1949, p. 130) hizo del conquistador que aparece en la imagen con un escudo decorado con un sol. Como él bien señalaba, por el color rojo de su pelo, don Pedro de Alvarado era conocido por el apodo de Tonatiuh. O sea, el Sol, que en este caso se pintó a modo de arma parlante en el escudo que portaba. Por esta razón, es probable que este conquistador sea el que también aparece con un escudo muy similar en el folio 250v del Lienzo de Tlaxcala (1981).

De acuerdo con Barlow (1995, p. 140), el segundo episodio es el que tuvo lugar en el sitio de San Martín Atezcapan, donde los españoles perdieron el pendón real y Cortés estuvo a punto de perecer tras caer al agua, en un puente que los españoles dejaron mal cegado ${ }^{14}$. Hernán Cortés sería el conquistador que aparece de frente, al que un indígena en posición un tanto extraña agarra para sacarlo del agua, tal como confirman algunos relatos que Barlow (1989, pp. 211216) recogió alrededor de ese suceso. 
En el otro extremo de la escena (folio $24 \mathrm{r}$ ), como ya se ha dicho, se representaron eventos paralelos pero, en este caso, relacionados con la entrada de los bergantines a Tenochtitlan (aunque los bergantines no se pintaron en el folio). Claro que la guerra la encabezó Cortés en este lado de la isla y, por tanto, antes de caer en el puente mal cegado de San Martín, en Tlatelolco. En cualquier caso, dice Sahagún con respecto a la batalla que tuvo lugar en esta otra parte de la ciudad:

Como hubieron descubierto los caminos por donde podían andar los bergantines, pusiéronse a gesto de guerra en los mesmos bergantines, con determinación de destruir a los mexicanos [...]. Y muchos de los mexicanos que tenían las casas dentro en el agua, como comenzó la guerra por el agua comenzaron a huir con sus hijos y con sus mujeres. Algunos llevaban a cuestas a sus hijos, y otros en canoas. (Sahagún 2000, libro XII, cap. 30 , p. 1211) ${ }^{15}$

El único paralelo pictográfico para esta escena lo encontramos en el folio $89 \mathrm{~V}$ del Códice Vaticano A que muestra que en el año 3-Casa, ó 1521, fue la conquista de Tenochtitlan, dedicando un espacio a una barca en medio de las aguas con un remero llevando a lo que parece ser una familia.

Aunque Sahagún no especifica a dónde transportaron a las mujeres y a los niños, Torquemada (1975, vol. II, libro 4, cap. 93, p. 283) dijo, un siglo después, que las mujeres fueron llevadas a Tlatelolco. Una decisión poco probable teniendo en cuenta que en esa parte de la isla se estaba librando simultáneamente una cruenta batalla.

\section{LA COLONia (ff. 24v-25v)}

Después de tres grandes escenas históricas, ocupando dos páginas cada una, el Códice Azcatitlan comienza a partir de ahora un formato distinto, al narrar sobre una misma página varios episodios diferentes. Es muy probable que en la parte superior de cada página se hubiera dejado espacio para representar los recuadros de los años ${ }^{16}$, de manera muy similar a como se encuentran en la primera sección del códice. Y es que si se toma en cuenta el tamaño de los recuadros de esa primera parte, se puede observar que el pintor de la tercera sección dejó espacio más que suficiente para pintarlos en esta otra parte de su obra.

La organización del documento en forma de anales, con una fila horizontal de años en su parte superior, implicaría una organización pictográfica vertical similar a la del Códice Vaticano $A$ o el Códice Telleriano-Remensis, donde los eventos históricos estarían en correspondencia con los años arriba señalados. Aunque de manera no muy rígida, ésta es precisamente la organización que se manifiesta en la tercera sección del Códice Azcatitlan. No es muy claro cómo había pensado relacionar el pintor los eventos con su correspondiente año. Una comparación con otros anales, como la Tira de Tepechpan o el Códice 
Mexicanus, sugiere que habría sido a través de una línea que conecta el evento con el correspondiente año. La lógica interna de los anales horizontales implica que los eventos representados debían mostrar un patrón cronológico a través del cual los acontecimientos más antiguos estarían a la izquierda y los más recientes a la derecha. Tomando en cuenta estas consideraciones, sugerimos que ésta es la lectura de los folios $24 \mathrm{v}$ al $25 \mathrm{v}$.

\section{Folio 24v: Del año 1524 a 1533 (Figura 5)}

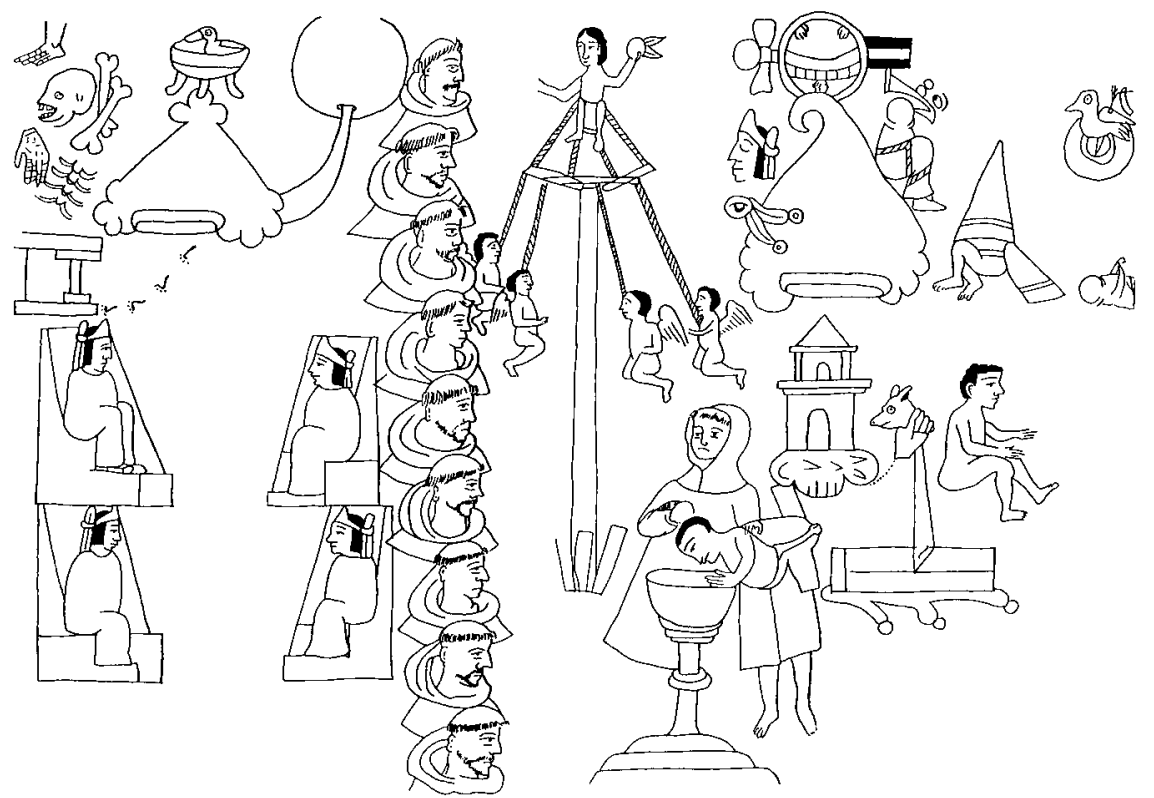

FIG. 5 - Del año 1524 a 1533 (folio 24v del Códice Azcatitlan).

La primera escena se encuentra en la esquina superior izquierda del folio. En ella se ven algunos huesos humanos (un pie, una mano, unas vértebras, un cráneo y dos fémures) al lado de un cerro en cuya cima hay un recipiente de tres patas, el cual contiene un ave. El cerro está conectado con un círculo a través de lo que parece un camino.

Una escena muy similar la hallamos en el folio 45r del Códice Aubin, en el año 7-Casa (1525). Allí también se representó un cerro con un recipiente de tres patas en su cima. Al lado se pintó además un bulto mortuorio con el glifo de una cabeza de águila junto a una huella de pie que baja (Figura 6a). Un texto en náhuatl explica: Nicā miquito yn quauhtemoctzin hueymollan, o sea, « Aquí murió 
Cuauhtemoctzin en Hueymollan ». Esto quiere decir que la cabeza del águila y la huella de pie representan el glifo onomástico de Cuauhtemoc («Águila que desciende »), mientras que el cerro con el recipiente es el lugar donde tuvo lugar su muerte. Dicho topónimo debe entonces leerse como Hueymollan (« Junto al Gran Mole »), recurriendo el pintor a un molcajete o molcaxitl para poder leer molli o mole ${ }^{17}$. Un tipo de recipiente que todavía hoy se usa para servir éste y otros tipos de salsas.
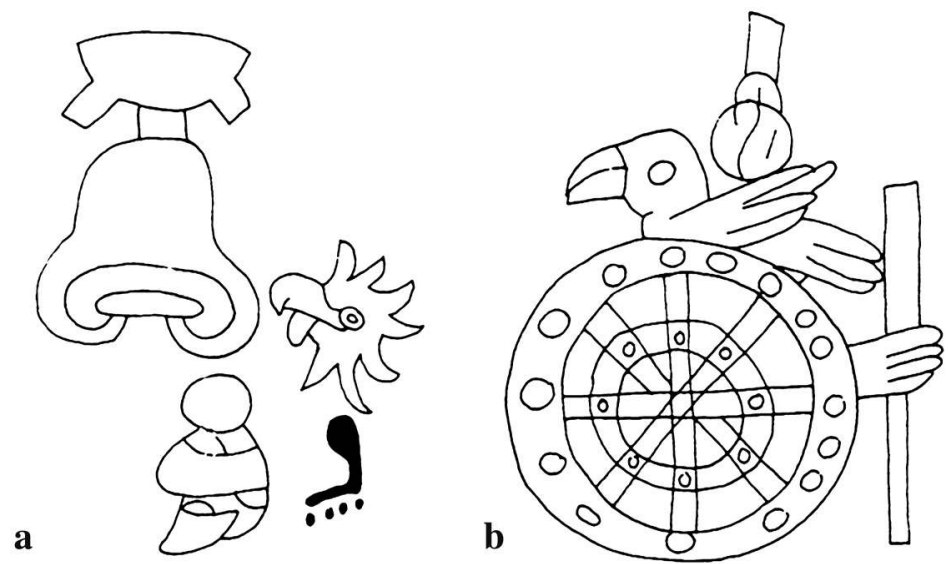

FIg. 6-a) Hueymollan en el Códice Aubin (folio 45r). b) Santo Domingo en el Códice Aubin (folio 46r).

En cuanto a la muerte del señor Cuauhtemoc, decía Cortés (Quinta carta, 1992, pp. 236-237) que, al haber sido avisado de una conspiración en contra de los españoles por él encabezada, lo mandó ahorcar junto con Tetlepanquetzal, señor de Tlacopan, como también confirmaba Díaz del Castillo (1992, cap. 177, pp. 469-470) entre otros cronistas. En cualquier caso, el suceso fue de tal impacto que quedó registrado en muchísimas fuentes. En el folio $6 \mathrm{r}$ del Manuscrito Mexicain núm. 217 se dijo que en el año 7-Casa, nican miquico. yn quauhtemoctzin tlacotzī oquitzin hueymollan yn momiquilito quinpilloque pochotl, o sea, "Aquí murieron Cuauhtemoctzin, Tlacotzin y Oquitzin en Hueymollan ${ }^{18}$. Allí fueron a morir. Los ahorcaron en un pochote ». El folio 15v del Manuscrito Mexicain núm. 40 relata ese mismo evento de la siguiente manera: nican huilohuac yn hueymolan yn opan miquito yn tlaloque nohuiyanpa yn nican mexico. Auh yn Cuauhtemoctzin quimistlacahui yn S.tiago cotzte mexica. Su traducción sería: "Aquí fueron a Hueymollan. Allá fueron a morir los tlatoque de todo México. Y Cuauhtemoc engaño/acusó falsamente a Santiago Cotzte, mexica ». Otras pictografías, además del Códice Aubin que ya hemos visto son: el folio 90r del Códice Vaticano $A$, donde se muestra que del año 10-Caña a 12-Casa [sic] 
Cuauhtemoc y Tlacotzin fueron ahorcados en un árbol (véase nota 18); la página 15 de la Tira de Tepechpan, la cual asocia la misma escena con el año 6-Tecpatl (1524) y añade la glosa Y hueymola huilovac ompa mique y tlatoque, "A Hueymollan fueron. Allá murieron los tlatoque »; o la página 78 del Códice Mexicanus, que sin embargo optó por pintar un escudo con una macana y una espada, símbolos de la guerra, conectados al glifo de un molcajete con un objeto no identificado (¿un ave?), todo asociado al año 7-Casa.

El cerro de Hueymollan está conectado a través de cuatro huellas de pie con un tecpan o palacio y cuatro gobernantes sentados en sus tepotzoicpalli (tronos con respaldo). Ninguno de los cuatro va acompañado por sus respectivos glifos onomásticos o toponímicos, lo que hace particularmente difícil su identificación. No obstante, una posible analogía de la escena se encuentra en la página $78 \mathrm{del}$ Códice Mexicanus, donde una serie de huellas de pies relaciona el glifo de Hueymollan con el de un gobernante indígena. Según su glifo onomástico se trata de Motelchiuhtzin, el nuevo quauhtlatoani, sucesor de Cuauhtemoc ${ }^{19}$. Un glifo onomástico casi idéntico está en el folio 45v del Códice Aubin. En base a la fuerte similitud entre esta escena en el Códice Mexicanus, se puede sugerir tentativamente que la presencia de los cuatro gobernantes en el Códice Azcatitlan, representa la instalación de Motelchiuhtzin en su cargo, siendo reconocido por otros tres señores ${ }^{20}$.

Desde luego, hay varios detalles en la escena de Hueymollan en el Códice Azcatitlan que no se pueden explicar. Por ejemplo, el ave dentro del molcajete, que parece más bien un pato. Tampoco se entiende qué significa el círculo que se conecta con Hueymollan a través de un camino. En realidad, da la impresión de que este elemento no se terminó de dibujar, aunque es interesante notar que debido a que en la parte superior de este folio se dejó espacio para los recuadros de los años, fue esa planificación la que provocó que el círculo quedara cortado ${ }^{21}$.

La siguiente escena del folio $24 \mathrm{v}$ muestra nueve bustos de hombres, con las cabezas tonsuradas, frente a un palo volador. Las cabezas tonsuradas son fácilmente reconocibles como las de los frailes franciscanos. Aunque el códice solamente representa nueve bustos, es muy probable que la imagen se refiera a la llegada de los « doce » franciscanos que en 1524 vinieron a la Nueva España para comenzar la evangelización de las tierras recién conquistadas. Casi todas las fuentes históricas del centro de México se refieren a este evento por la importancia de la llegada de la palabra de Dios. Lo hace, por ejemplo, el Lienzo de Tlaxcala (1981, ff. 239v-240r) en dos escenas: una con la llegada de los doce y otra con el bautizo de los señores gobernantes del lugar, en una secuencia muy similar a la del Códice Azcatitlan.

El folio 45r del Códice Aubin no menciona directamente a los doce en el año 6-Pedernal (1524), donde se dice: nican tzintic in teoyotl yqtc peuh in ye techmachtia padreme, o sea: «Aquí comenzó el teoyotl. Entonces empezó que los 
padres nos enseñaron ». Sin embargo, el folio 6r del Manuscrito Mexicain núm. 217 es mucho más explícito en la entrada del mismo año: yn ipan maxitico $p^{e}$ me san fran ${ }^{c o}$ teopixqt om omê [...] yn o yuh maxitico niman yc tzintic yn teoyotl yquac peuh yye motemachtilia padreme. Su traducción sería: « En el año llegaron los padres, los franciscanos 12 [...] Cuando llegaron empezó el teoyotl ${ }^{22}$. Entonces comenzó que los padres nos enseñaron ».

Las llegadas de autoridades españolas eran acontecimientos dignos de celebrarse con varias actividades festivas. Los Anales de Juan Bautista dan una buena idea de lo que eran estas fiestas cuando describen la que tuvo lugar a la llegada del virrey don Gastón de Peralta en 1566:

[...] entonces partieron los xochipilteca que se fueron a colocar allí en Tepeyacac [...] y los guerreros de todos los pueblos, junto con los mexicanos, allá en Tepeyacac se reunieron [...] llegó el virrey don Gastón [de Peralta]... y por las escopetas con las que lo recibieron murieron cuatro [...].

[...] entonces por primera vez le asaetearon toros al señor virrey, allá en los portales fueron asaeteados los toros y el señor lo observó desde el celar.

[...] entonces hubo palo volador en el exterior del palacio con lo que alegraron al señor, se danzó y se interpretó el axochitlacayotl, se arreglaron muy bien en México para danzar [...]. (Anales de Juan Bautista 2001, párrs. 36-38)

Aunque no existen referencias históricas a eventos similares en relación a la llegada de los doce, lo habitual de tales eventos en algunos anales sugiere que éstos eran algo normal en la Nueva España, y posiblemente en Mesoamérica, tanto en el tiempo prehispánico como en el colonial temprano. La específica mención del palo volador en relación a la llegada de Gastón de Peralta indica que esta actividad formaba parte de este tipo de festividades ${ }^{23}$.

Después del palo volador se encuentra la escena del bautizo, asociada a un complejo de glifos que consisten de una estructura europea (probablemente una iglesia), la cabeza de un perro agarrado del cuello por una mano y una coa (instrumento para sembrar) conectada con tablones de madera y agua. Al lado un hombre desnudo. Graulich (1995, p. 144, nota 95) vio una asociación de todo este conjunto con el folio 90v del Códice Vaticano $A$, que sin duda contribuye a entender qué es lo que aquí se quiso narrar (Figura 7).

En el Códice Azcatitlan, como en el Códice Vaticano A, vemos que la persona que recibe las aguas por parte de un sacerdote no lleva un glifo onomástico asociado. Posiblemente porque tan sólo se trata de una alusión genérica al bautizo en los templos cristianos, de ahí la representación de una iglesia en ambos documentos. En el Códice Vaticano A, el recién bautizado está unido a una autoridad española, que a la vez está frente a un indígena esclavo porque lo sujeta con una cuerda o mecate atado al cuello. En este documento se indica, además, a través de dos coa sobre las aguas que salen de un cerro con un chapulín, que se estaba construyendo una albarrada en Chapultepec. 

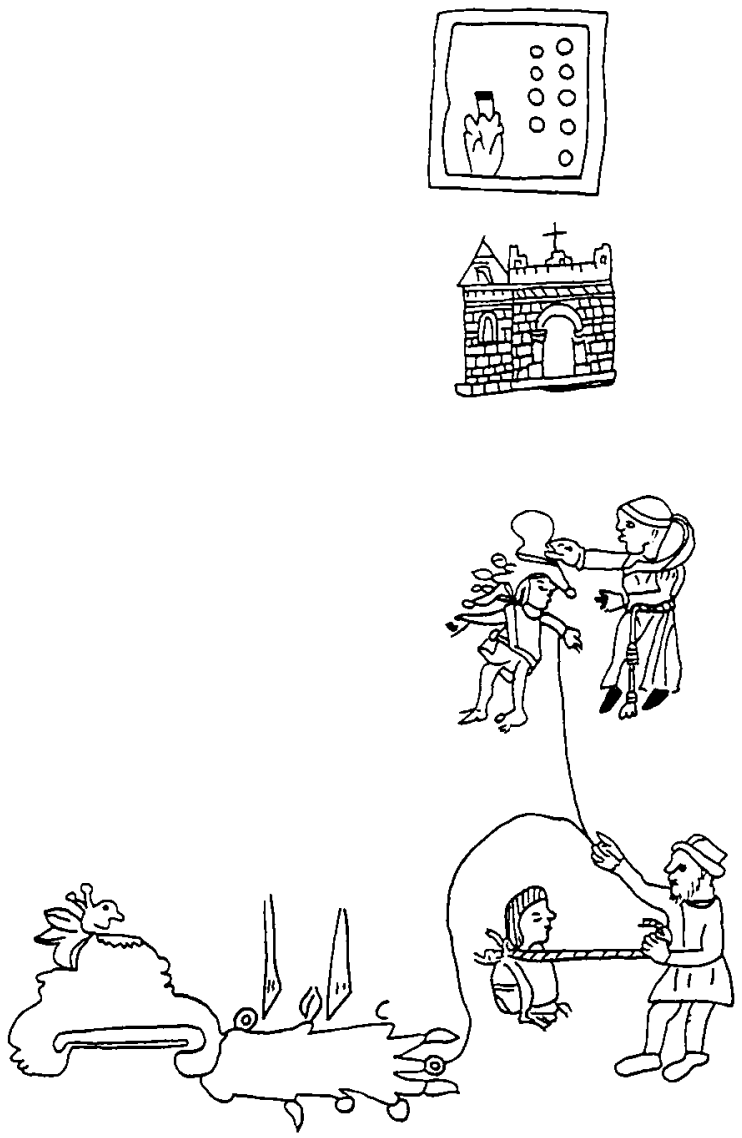

Fig. 7 - Año 9-Caña (1527) en el Códice Vaticano $A$ (folio 90v).

Estas dos escenas se pueden ver como dos eventos distintos que tuvieron lugar en el mismo año de 9-Caña ó 1527: el bautizo y el uso de esclavos en Chapultepec. No obstante, también se podrían leer como escenas relacionadas: « aunque nos bautizaron, nos utilizaron como esclavos en Chapultepec ». Pues bien, algo similar parece que es lo que se quiso expresar en el folio $24 \mathrm{r}$ del Códice Azcatitlan: «A pesar del bautizo en la iglesia, tomaron a muchos de esos bautizados como esclavos ». Así es como se podría leer la imagen del hombre desnudo - muy conocida en la iconografía mesoamericana para expresar esclavitud -, junto al instrumento del trabajo (la coa), que a su vez está unido al templo a través de una línea de puntos. Esto sin olvidar que también aquí se habla de la construcción de una albarrada en el agua, aunque ya no se pintó el glifo de Chapultepec. 
No obstante, el paralelo entre ambos documentos permite inferir que así fue. Tenemos entonces que a través de esta escena, el tlacuilo o pintor seguía quejándose con el mismo argumento que en el folio $23 \mathrm{r}$, y posiblemente $23 \mathrm{v}$, del Códice Azcatitlan: « Ya eramos cristianos y aun así... ».

Desconocemos la lectura del puño (¿sometimiento?) agarrando a un perro por el cuello. De cualquier manera, en el Códice Vaticano $A$ este acontecimiento tuvo lugar en 9-Caña, 1527, periodo al que también correspondería esta parte del folio del Azcatitlan. El Códice Aubin y el Manuscrito Mexicain núm. 217 registran el mismo evento en el año 10-Pedernal, 1528, cuando se dice en el primero de estos documentos yvan yquac moquetz yn ayotli chapoltepec, o sea, "Y luego se levantaron las obras de agua en Chapultepec ».

Llegados a este punto falta comentar el problema cronológico que hay entre algunas de estas escenas. Si como hemos visto, el folio $24 \mathrm{v}$ comenzaba con la campaña militar a las Hibueras, quiere decir que los hechos tuvieron lugar entre 1524 y 1526, que fue lo que duró dicha expedición. El problema es que la muerte de Cuauhtemoc tuvo lugar hacia 1525 y la llegada de los doce fue en 1524, antes de la marcha de Cortés. Esto quiere decir que si esta última parte del Códice Azcatitlan son unos anales, como nosotros creemos, estas escenas deberían estar al revés. Por tanto, y a modo de hipótesis, podemos decir que esta alteración estuvo quizás provocada por el objetivo del pintor: relacionar directamente la llegada de los doce con el bautizo de un señor indígena, como fue el caso en el Lienzo de Tlaxcala, ignorando en tal caso el rígido esquema cronológico y optando por un esquema de evento, siendo muy importante para él que ambas escenas estuvieran juntas.

La última escena del folio $24 \mathrm{v}$ se encuentra en la esquina superior derecha y se compone de un cerro curvado con varios elementos pictográficos a su alrededor. El glifo de un cerro curvado se lee normalmente como Culhuacan, pero al tener un escudo y una macana en su cima se nos está hablando de una guerra que ahí tuvo lugar. Dos documentos pictográficos nos ayudan a identificar el mismo suceso. El Códice Aubin, cuyo folio 46r está asociado al año 13-Caña (1531) y donde un texto dice: $y q[u i] c$ ye no ceppa ompeovac $y[n]$ colhuacan, o sea, «Entonces se fueron otra vez a Colhuacan». El otro es el Códice Mexicanus (p. 78) donde se registra asimismo un cerro curvado junto al glifo de guerra, pero en el año 12-Conejo (1530).

Ahora sabemos que este Colhuacan es en realidad Culiacan, en el norte de México, mientras que la escena de guerra se refiere a la desastrosa campaña militar organizada por Nuño de Guzmán (1530-1531) ${ }^{24}$. Son muchas las fuentes indígenas que se refieren a este episodio, debido a que Nuño de Guzmán utilizó la fuerza y la intimidación para reclutar soldados y tamemes del centro de México y Michoacan, muchos de los cuales murieron en las cruentas batallas. El Manuscrito Mexicain núm. 217 y el Manuscrito Mexicain núm. 40 son dos de los documentos que relacionan esta entrada con el año 12 Conejo (1530): 
Y entonces se fue Motelchiuhtzin a Colhuacan. Allí murió. (Manuscrito Mexicain núm. 217, folio 6v)

Aquí juntaron por primera vez a los de Colhuacan, la gente de todos los lugares, los gobernantes de las ciudades. Como soldados salieron. Muchos murieron allí, sólo pocos regresaron. (Manuscrito Mexicain núm. 40, folio 16r)

El Códice Azcatitlan muestra también que dos personas murieron en dicha campaña; un tlatoani llamado «Ojo-Agua » y otro con el nombre calendárico « 2-Viento (Ehecatl) ». Este último está representado como un bulto mortuorio, mientras que del primero solamente se ve la cabeza con los ojos cerrados ${ }^{25}$. Es curioso encontrar un nombre calendárico completo (numeral y signo) en un documento nahua porque, normalmente, en el centro de México sólo se da el nombre personal, mientras que en las regiones nahuas donde sí se da el nombre calendárico tan sólo se proporciona el signo pero no el numeral. Sea como fuere, como no se ha podido identificar a este personaje, tampoco se puede resolver este enigma. Para el señor «Ojo-Agua » hay una posible identificación. La lectura sería $a(t l)$-ix $(t l i)$, que podría ser un acercamiento nahua a "Andrés » y, por tanto, a don Andrés Motelchiuhtzin, quien, según el Manuscrito Mexicain núm. 217 murió en la campaña de Culiacan ${ }^{26}$. Lo corrobora la Crónica Mexicayotl (1992, p. 167) al decir que murió por herida de flecha.

Al lado derecho del cerro se encuentra la representación de un tocado cónico con la parte inferior de un cuerpo humano, muy similar al glifo de la página $78 \mathrm{del}$ Códice Mexicanus, junto al cerro curvado. El glifo se refiere al sitio de Yopitzinco porque el tocado está asociado a Xipe, el dios patrón de los Yope, y la parte inferior del cuerpo humano a un elemento fonético que se lee como -tzintli o «pequeño». De Yopintzinco dicen los Anales antiguos de México y sus contornos: icuac yaque yopitzinco mexica tlatilolca tepehuato. Es decir «fue cuando fueron a Yopitzinco los mexica-tlatelolca en son de conquista » (Barlow y McAfee 1989, pp. 220, 230).

Hay todavía más escenas pictográficas en el folio $24 \mathrm{v}$, pero están muy dañadas y quedaron cortadas, haciendo muy difícil su interpretación. A diferencia de Barlow, Graulich (1995, pp. 144, 146, notas 93 y 96) sostenía que no había razón para pensar que a esas escenas les faltara una parte porque la lectura estaba perfectamente encadenada con las del siguiente folio. Sin embargo, como aquí demostraremos, los acontecimientos que siguen en el folio $25 \mathrm{r}$ se remontan ya a la década de los 40 del siglo XVI, faltando así los datos históricos de la década de los años 30 de esa centuria, que estaría en la parte de un folio perdido.

En cuanto a las escenas que se pueden rescatar, vemos un ave perforada por un tipo de lanza o flecha, sobre una piedra con círculos concéntricos. Graulich (1995, p. 146, nota 96) señaló su similitud con la que aparecía en el folio 46r del Códice Aubin (Figura 6b), precisamente en el año de 1533, que sería el que correspondería a este folio perdido. Sin embargo, no se comprende por qué llegó 
a la conclusión de que el ave era una alusión al mes tozoztli, cuando en el Códice Aubin el ave flechada está sobre el glifo ideográfico de un mercado o tianguis (un círculo con trazos concéntricos). Algo que corrobora el texto alfabético que acompaña a esta escena al decir que se trataba del mercado de Santo Domingo. Ahora no tenemos dudas de que el ave era parte del componente fonético de este lugar, pues como señala Galarza (1996, p. 46), para la representación fonética de « Santo Domingo » se utilizaba tres elementos fonéticos: xantenamitl para decir " xan »; un ave o tototl con una flecha o mitl (un ave flechada) para expresar « toto-mi ». La combinación de esos tres elementos se lee como « Xantotomi», un acercamiento a « Santo Tomi(ngo)».

\section{Folio 25r: De la década de los 40 a 1566 (Figura 8)}

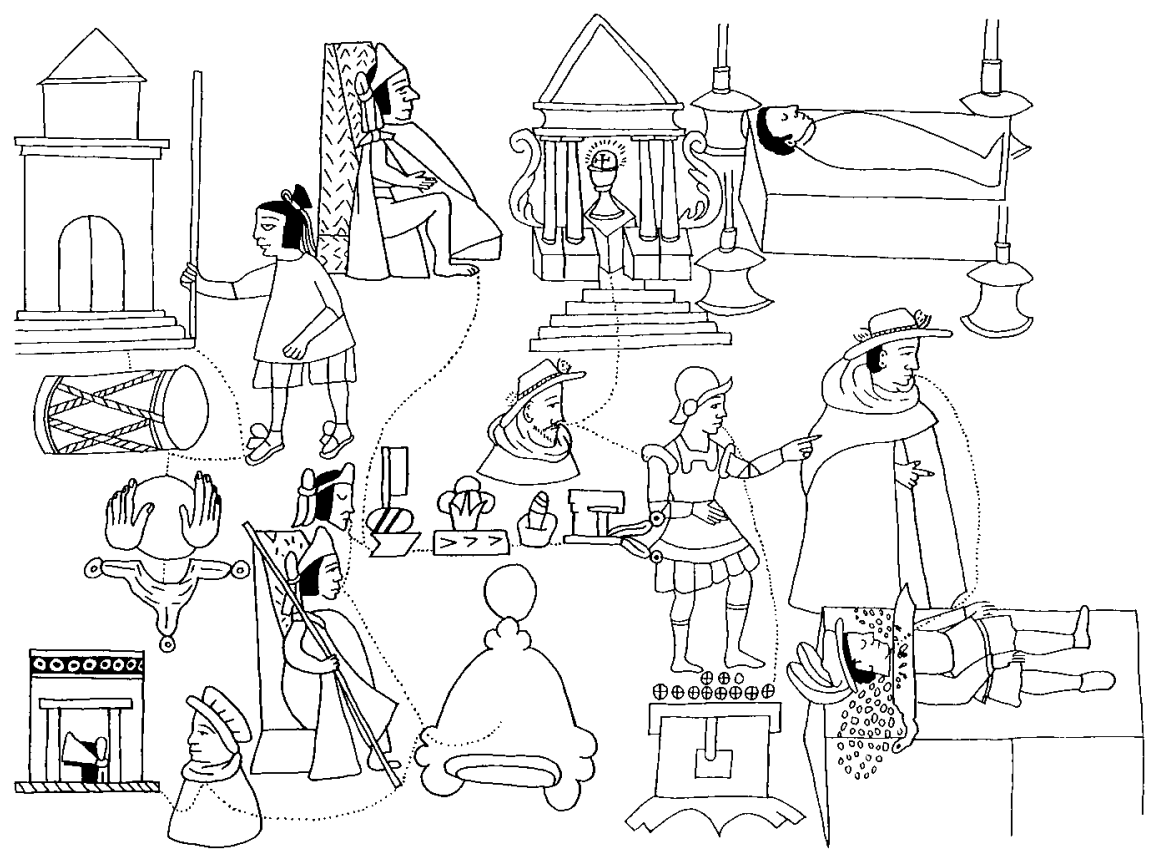

FIG. 8 - De la década de los 40 a 1566 (folio 25r del Códice Azcatitlan).

Si como hemos dicho, entre el folio $24 \mathrm{v}$ y $25 \mathrm{r}$ hay un folio perdido, en el lado recto de ese folio debían ir los sucesos de la década de los años 30, mientras que en el lado verso irían los de la década de los años 40 . Teniendo esto en cuenta, lo que hoy es el folio $25 \mathrm{r}$ comienza con una escena en el lado superior izquierdo, donde se dibujó una estructura europea (probablemente una iglesia), conectada a través de una línea de puntos a un tambor y a un hombre indígena con bastón en mano. Como ya se ha dicho, este bastón indica que el personaje es un juez, que en este 
caso parece estar midiendo. El juez y el tambor están a su vez conectados con un círculo y dos manos, una a cada lado, y éste con unas aguas que parecen fluir en tres direcciones. Hasta ahora no se ha podido relacionar estos sucesos con evento histórico alguno ${ }^{27}$.

La siguiente escena es muy compleja. Se trata en realidad de cuatro escenas menores conectadas a través de líneas punteadas. La lectura parece empezar en la parte superior donde se encuentra un gobernante indígena con la xiuhhuitzolli ceñida en su cabeza, sentado en un tepozicpalli o asiento con respaldo. No tiene ningún glifo onomástico, por lo que a este nivel todavía no se le puede identificar. Una línea lo conecta con la cabeza de un gobernante que está dibujado con los ojos cerrados y que, por tanto, está muerto. Delante de la cabeza hay cuatro glifos: un paralelogramo con una piedra y una bandera, un campo con una flor, lo que parece ser un molcajete con su tejolote, y una casa con agua. El primero de esos glifos se puede leer como « Esteban », el segundo como « Xochimilco », mientras que el tercero y cuarto, conjuntamente, como «Tlaxcala» ${ }^{28}$. La cabeza del gobernante muerto está a su vez conectada con la figura de otro gobernante, con la particularidad de que lleva un bastón en su mano. Como arriba se indicó, esto quiere decir que se trata de un juez, en este caso con la categoría de gobernador (juez-gobernador) por llevar la xiuhhuitzolli ceñida a la cabeza y estar sentado sobre un tepotzoicpalli. Una línea conecta a este juez con un cerro y un círculo, que ahora es claramente el topónimo de Tlaxcala (ver nota 21). Otra línea lo conecta al busto de un hombre vestido a la usanza europea, el cual está unido a un tecpan en cuya puerta hay una xiuhhuitzolli.

Será nuevamente el Códice Aubin el que nos lleve a identificar esta compleja escena, al decir que en el año 10-Conejo (1554): Nica [n] momiquili yn don diego tevetzq[ui]titzin. XI. Mayo yn omotopilmacac don Esteva de cozma. Juez. XXVI Junio, o sea: «Aquí murió don Diego Tehuetzquititzin, el 11 de mayo. El bastón de mando se dio a Don Esteban de Guzmán, como juez el 26 de junio ».

Parece, entonces, que el gobernante en la parte superior del folio es don Diego Tehuetzquititzin, gobernador de Tenochtitlan entre 1541 y 1554, quien al morir (cabeza del tlatoani con ojos cerrados) fue sucedido por don Esteban de Guzmán ${ }^{29}$. Lo corrobora también el Manuscrito Mexicain núm. 40 al referirse al mismo suceso, en el año 10-Conejo: nican momiquili yn D Diego tehuetzquiti. Es decir: «Aquí murió don Diego Tehuetzquititzin », aunque paradójicamente el pintor se equivocó al glosar la pictografía. Bajo la imagen del juez y de Tehuetzquititzin muerto puso el nombre del siguiente gobernador indígena de Tenochtitlan (« don christoval»), mientras que bajo la imagen de don Cristóbal escribió el nombre del juez («D[o]n esteban ») ${ }^{30}$.

Don Esteban de Guzmán era un noble indígena de Xochimilco que había ostentado el cargo de alcalde (1542) y gobernador (1553) en su ciudad de origen. Sin embargo, su fama se debía a su labor como juez-gobernador en varios pueblos a donde fue a ejercer su autoridad. Sabemos que en 1550 estuvo en Teutalco, en 
1554 en Tenochtitlan y en 1560 en Tlatelolco (Pérez Zevallos 2003, p. 43). El Códice Azcatitlan lo registró precisamente en Tenochtitlan, a donde fue para hacerle la residencia a Tehuetzquititzin. La página 83 del Códice Mexicanus muestra pictográficamente la misma cadena de eventos: la muerte de Tehuetzquititzin y a un hombre con un bastón que viene de Xochimilco llamado to[totl] ix[tepan] o Don Es[teban].

Los Anales antiguos de México y sus contornos resuelven lo demás de la escena cuando dicen que en el año 11-Caña (1555) motlalli juez don estevan de cozmna hualla tlaxcallan in nican tlatilolco tlapieco nican catca totecpa $(n)$ ch(an). Es decir: « Se instaló como juez, don Esteban de Guzmán. Vino de Tlaxcala aquí a Tlatelolco para tomar posesión. Aquí estuvo en nuestro palacio » (Barlow y McAfee 1989, pp. 222, 236-238). El texto es una lectura precisa de lo que se representa pictográficamente en el Códice Azcatitlan. O sea, que tras su estancia en Tenochtitlan se fue a Tlaxcala y de allí, enviado por el virrey Velasco, al tecpan o palacio de Tlatelolco.

La siguiente escena del folio $25 \mathrm{r}$ parece estar constituida por dos sucesos, asociados a dos años distintos, aunque ambos tienen a una misma persona como protagonista. Se trata de un hombre representado de medio busto, con barba y ropa europea, pero que no tiene glifo onomástico y no ha podido ser identificado. De su boca salen dos líneas punteadas: una hacia una escena en la parte superior y otra hacia una escena en la parte inferior.

En la escena superior se representa una construcción europea, levantada sobre las escalinatas de una estructura piramidal indígena. Está compuesta de un basamento con cuatro columnas, dintel y frontón. En el espacio entre las columnas se encuentra un cáliz con la sagrada ostia. Al lado derecho se vela el bulto de un muerto que yace sobre una mesa que tiene alrededor cuatro candelabros. Varios documentos tienen un registro similar y nos permiten leer la escena del Códice Azcatitlan sin equivocaciones. Es el caso del Códice Aubin, donde en el año 2-Caña (1559) se ve también una estructura europea, añadiendo el texto alfabético: Iquac ylhuitzin ypan Sant Andres yn ipan neteochivalloc don callos Emperador. Es decir: « Entonces en la fiesta del santo Andrés se celebró la misa para el Emperador Don Carlos ». El Manuscrito Mexicain núm. 217 tiene una entrada similar en ese mismo año: «Y entonces fue hecho templo de madera, el monumento allí en San José, mientras se rezaba por el Emperador Don Carlos Quinto ». Otras representaciones son las de la página 18 de la Tira de Tepechpan, donde el año 2-Caña está asociado a una iconografía que sólo representa un bulto mortuorio coronado, conectado a una corona más grande; la página $83 \mathrm{del}$ Códice Mexicanus que en el mismo año pinta una estructura con lo que parece una vela; el Códice de Tlatelolco (última escena) que registra un gran túmulo con el escudo de los Habsburgo; o el Códice en Cruz (en el cuarto ciclo de 52 años), que en el año 2-Caña también representó una estructura colonial con una glosa que dice « domolo » para túmulo (Dibble 1981, p. 57). 
No hay duda, entonces, de que todas estas fuentes, y también el Códice Azcatitlan, hacían referencia al túmulo imperial que se erigió en la capilla de San José de los Naturales, en el patio del convento de San Francisco, para recordar la muerte del emperador Carlos V, el 21 de septiembre de 1558. Con este motivo se hicieron ceremonias conmemorativas en la capital de la Nueva España:

2-Acat1, 1559 [...] Y también en éste vino a conocerse, llegó la noticia de España de que había muerto el gran tlahtohuani don Carlos Quinto, emperador de Roma. Entonces se levantó, se dispuso un templo de madera, un monumento en la capilla de San José de San Francisco de México porque allí se hicieron los funerales, porque allí se dijo la misa por el emperador don Carlos Quinto en la festividad de san Andrés Apóstol. (Chimalpain 2003, pp. 269, 271)

Ahora bien, según la minuciosa descripción del túmulo realizada por Cervantes de Salazar (1972) ${ }^{31}$, éste fue diseñado por el arquitecto Claudio de Arciniega y

en el entretanto que se acababa, era de ver la gente que concurría, así de los españoles como de los naturales, para ver los soberbios y sumptuosos principios que llevaba [...]. También se dio noticia a los caciques y gobernadores. Finalmente, [...], concurrieron de los españoles y naturales, tanto que la ciudad de México nunca estuvo tan de ver como estuvo entonces, porque por las plazas y calles se veían por horas gentes de fuera [...]. (Cervantes de Salazar 1972, p. 184, 205-206)

La larga duración de la construcción del túmulo (3 meses) y las elaboradas exequias de Carlos V son las que entonces explican la gran atención que recibió el túmulo y el hecho de que esté plasmado y descrito en tantas fuentes.

En cuanto a la segunda escena conectada al señor en el centro del folio, tenemos que es muy diferente a la de Carlos V. En este caso se trata de un soldado que apunta hacia la derecha del folio y que está conectado con una caja de madera y once monedas. Los elementos pictográficos sugieren que el asunto representado tiene algo que ver con dinero. Debe haber tenido además lugar entre 1558 y 1566, o sea, entre los años de la misa de Carlos V y el siguiente evento registrado.

El Códice Aubin dice que en el año 7-Pedernal (1564) se impuso el tributo de un peso y tres tomines. La página $84 \mathrm{del}$ Códice Mexicanus tiene para ese mismo año una compleja escena que también incluye la representación de un peso y tres tomines. La importancia de este evento radica en que hasta 1564, los pueblos indígenas pagaban su tributo en especie (mantas, maíz, etc.), sin embargo, a partir de ese año el tributo tuvo que hacerse en dinero y el soldado así parece pregonarlo. En relación al dinero, es importante notar que durante la Colonia el peso valía ocho reales, lo que tentativamente se puede relacionar con la escena del Azcatitlan en la que se dibuja una hilera de ocho monedas y otra de tres. O sea, ocho reales (= un peso) y tres tomines. Si esta suposición es correcta, el Códice Azcatitlan estaría entonces registrando el cambio de una sociedad que tributaba 
en especie a una sociedad que tributaría monetariamente para vivir como la española. De esa manera lo expresan, precisamente, los Anales de Juan Bautista:

[...] así ordena el visitador, así tributarán, el trabajo público lo dejarán junto con el zacate además de todo lo que les imponía de tributo en el palacio de ustedes. Todo se suspende por un peso y tres tomines; así me lo dijo el visitador, que como españoles aquí vivirán. (Anales de Juan Bautista 2001, párr. 171)

Retomando el análisis pictográfico tenemos que, frente al soldado, se encuentra un señor español, de cuya boca sale una línea punteada hacia un personaje que yace muerto sobre una mesa, tras cortársele la cabeza. Varias fuentes históricas hablan sobre este evento por el impacto que produjo su crueldad. El Manuscrito Mexicainnúm. 40 registra que en el año 9-Conejo (1566):

Auh çan no ypan Ce xihuitl yaoyotl quitohuaya yn ipilhuan yn Conquistadorti ypan julio. $X X$ mani metztli. Yn oquimilpique Alonso Dabilia yhuan iteiccauh [yhuan] yn marques yhua[n] yn iteccauh ypilhuan mochintin yn tepehuanime yn miquico ye ilhuitl mani metztli Agosto Alonso Dabila yhuan n iteicauh San quinquechcocotonque San yoltimanca senca tlamahuiçoli ynic micque Senca yuhquin yagoyotl yn yaotlapixque necoc mohuipanque yca yn intepostzinacantopil ynic hualquisque yn Corte Do[c]tor çabino cabros. (Y también en este año llamaron a la guerra los hijos de los conquistadores, a 20 días del mes de julio colgaron a Alonso Dávila [Alvarado] y a su hermano menor y al marqués y a su hermano menor, hijos [de Hernán Cortés]. Todos eran conquistadores. Murieron en la fiesta del mes de agosto, Alonso Dávila y su hermano. Solamente [a ellos] les cortaron el cuello. Fue muy asombroso cómo murieron; como si fuera en la guerra, vigilaron mucho de uno y de otro lado con sus lanzas. Así salieron [los de la] corte, doctor Francisco de Ceynos [Obregón]). (Medina González 1998, pp. 110-111)

El Códice Aubin muestra, para ese mismo año 9-Conejo, la representación de tres bustos masculinos, de los cuales dos tienen sangre corriendo por su cuello. El texto en nahuatl dice ynic xvi Julio y martestica analloque y marq [ue]s yva [n] alonso lavila yva[n] yteyccauh caltzaq[ui]tloq[ue] Auh yn omicq[ue] alonso lavila yva[n] yteyccauh don p[edr]o gomzalez, o sea: «El 16 de julio, martes, fueron traídos el Marqués y Alonso Dávila y su hermano menor. Se los encarcelaron. Y murieron Alonso Dávila (o de Ávila) y su hermano menor don Pedro Gil González ». La página 85 del Códice Mexicanus registra dos cabezas, también en el año 9-Conejo, mientras que la página 18 de la Tira de Tepechpan pintó esas mismas dos cabezas, pero decapitadas con sangre. No obstante, su texto dice equivocadamente que esto tuvo lugar en 10-Caña y 11-Pedernal.

Ahora bien, sobre lo que todos estos textos alfabéticos y pictográficos están hablando es sobre el supuesto intento por parte de don Martín Cortés de tomar el poder en la Nueva España y coronarse como rey ${ }^{32}$. Un asunto que está relacionado con el momento en el que tras la muerte del virrey don Luis de Velasco, la Nueva España estuvo gobernada por la Audiencia, donde al parecer 
había un grupo de conquistadores - e hijos de éstos - que querían poner a Martín Cortés - hijo de Hernán - en el trono. La traición fue sin embargo descubierta y todo un grupo de personas encarceladas o exiliadas. Debido a que se llegó a la conclusión de que Alonso Dávila y su hermano Gil Gonzálezfueron los principales conspiradores, se dio la orden de que éstos fueran degollados.

Pero todo este juicio tiene la apariencia de haber sido improvisado por la Audiencia, pues Torquemada (1975, vol. II, libro 5, cap. 18, p. 394) describe con asombro cómo degollaron a los hermanos « en sendas mulas, vestido Alonso de Ávila de negro y una ropa o turca de damasco pardo, con gorra de terciopelo con una pluma negra y una cadena de oro al cuello, que el traje en que estaba cuando le prendieron ». El dibujo del Códice Azcatitlan representa precisamente a Dávila con su gorra de plumas y un tipo de machete con el que le cortaron el cuello. Una línea punteada conecta el cuello con la boca del español que está junto a él. Debe tratarse de Francisco de Ceynos, el oidor que tuvo el mando de la Audiencia después de la muerte del virrey. De hecho, así lo corrobora, no sólo la parte alfabética sino también la pictográfica del Manuscrito Mexicain núm. 40 (Figura 9).

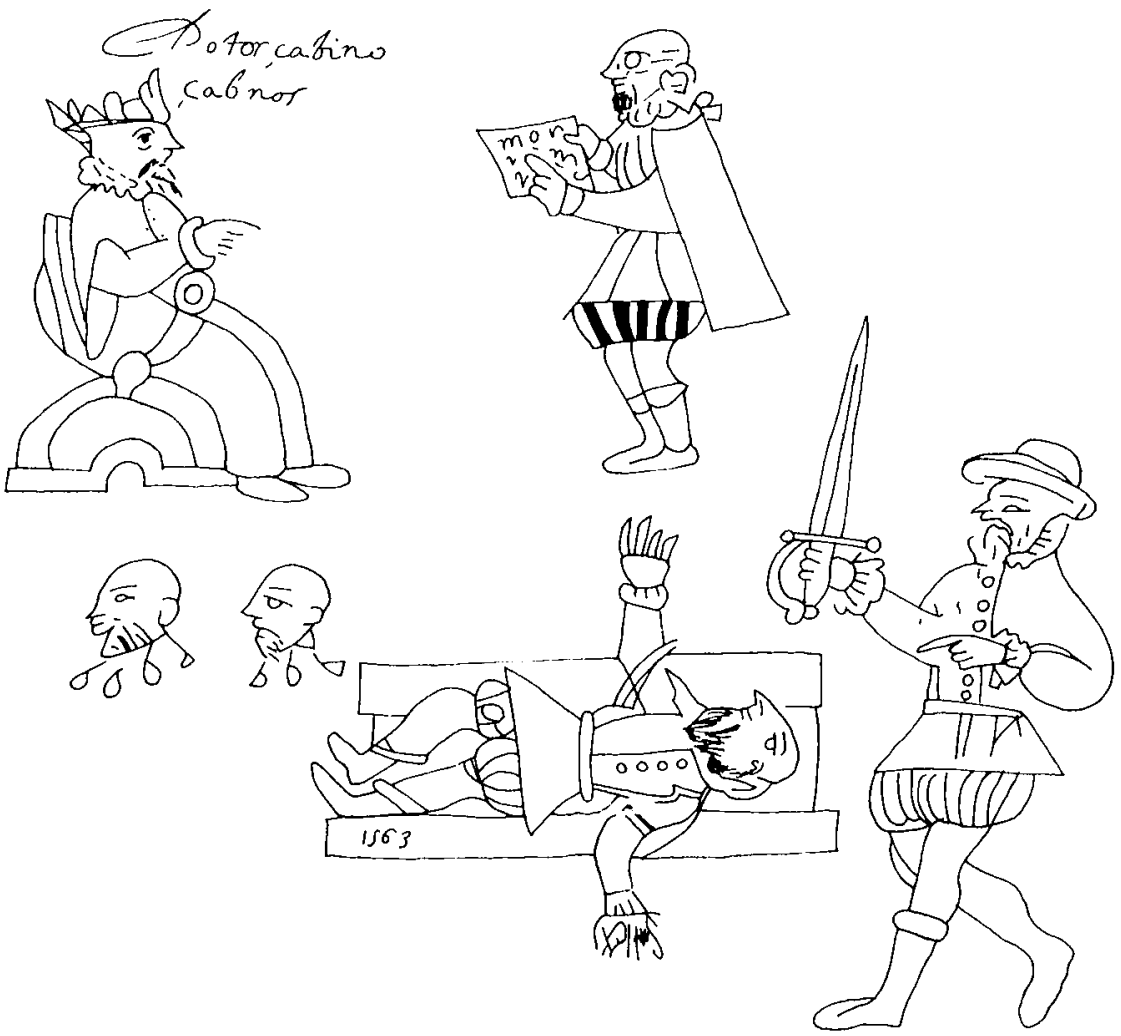

FIG. 9 - Decapitación de Alonso Dávila en el Manuscrito Mexicain núm. 40 (folio 18v). 
En el dibujo se ve a Ceynos, que curiosamente está representado como un rey, emitiendo la condena. Un español lee la sentencia y al lado hay otro listo para ejecutarla. Es decir, para cortar la cabeza del hombre tumbado. Aunque aquí no se plasma el corte mismo, como lo está en el Azcatitlan, las dos cabezas con gotas de sangre al lado indican que se trata de Alonso Dávila y su hermano Gil González, ambos mencionados en el texto en nahuatl ${ }^{33}$.

\section{Folio 25v: Del año 1566 a 1568 (Figura 10)}

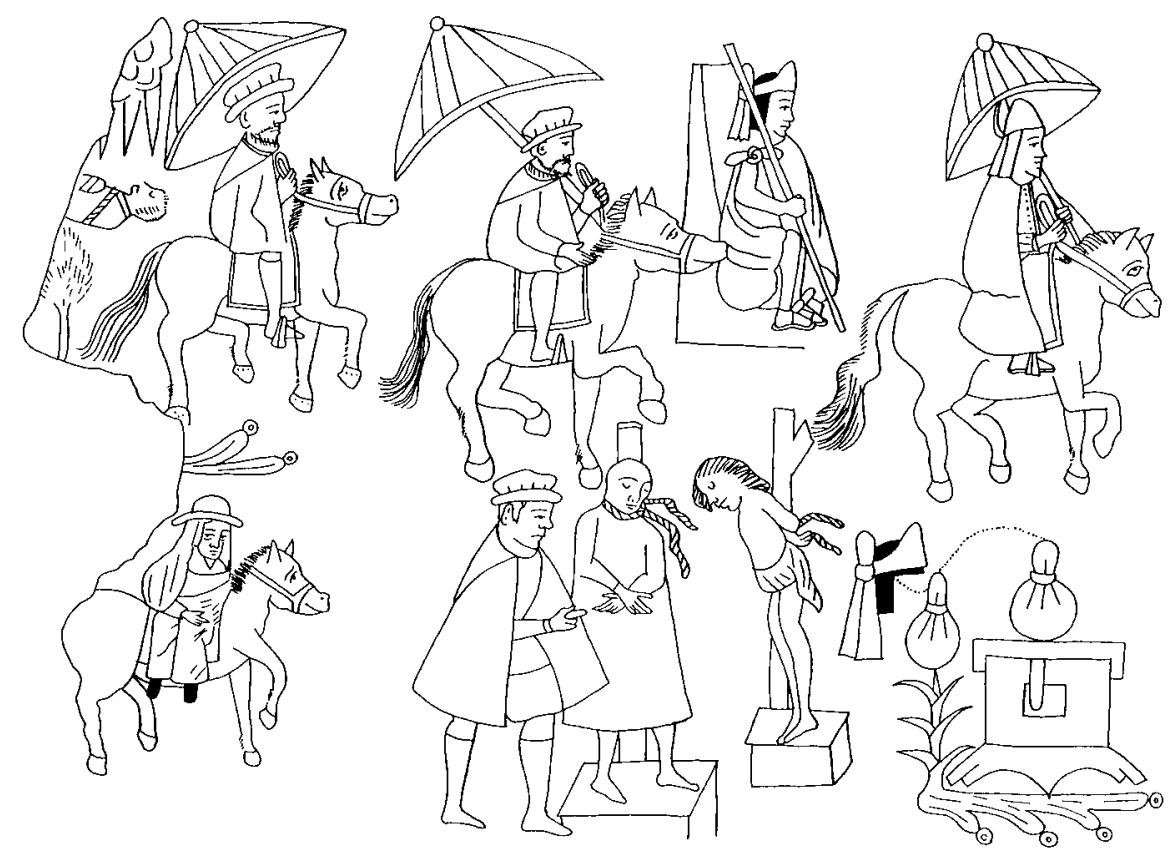

Fig. 10 - Del año 1566 a 1568 (folio 25v del Códice Azcatitlan).

El último folio del Códice Azcatitlan está muy deteriorado en la parte donde comienzan a narrarse los sucesos. En él se ve un dibujo muy estilizado de lo que parece una nube con lluvia. Abajo, un bulto mortuorio sobre el cual hay una piedra (¿lapidación?) y el glifo toponímico de un árbol y una corriente de agua. Pero nada más se puede decir de eso. A continuación tenemos la representación de una serie de personajes españoles montados a caballo, además de un señor indígena sentado en su tepotzoicpalli. El bastón que lleva en la mano indica nuevamente que se trata de un juez-gobernador, puesto que también lleva ceñida la xiuhhuitzolli. 
No es claro si estamos ante una sola escena o ante varias. Dos de los señores de la parte superior parecen ser autoridades civiles, mientras que el que encabeza la cabalgata es claramente un obispo. El personaje a caballo en la parte inferior del folio parce ser un clérigo, pues su imagen es muy similar a la del clérigo que se pintó en el folio $252 \mathrm{r}$ del Lienzo de Tlaxcala $(1981)^{34}$. En cualquier caso, es muy probable que estos señores representen las llegadas de ciertas autoridades coloniales al Altiplano. Para ubicarlas cronológicamente es necesario identificar la última escena de este folio, concretamente la que se encuentra en la esquina inferior derecha.

En ella vemos a un español apuntando a dos personajes en una picota, uno atado por el cuello y el otro por las manos. Los ojos cerrados indican que ambos ya han muerto. Al lado se encuentra una xiuhhuitzolli, conectada a través de una línea punteada con dos bolsas, un baúl de madera y un glifo toponímico, compuesto de una caña y agua. El evento es relativamente fácil de identificar porque en el Códice Aubin, en el año 11-Pedernal (1568), se muestra una escena muy similar con dos personas colgadas. Además hay una descripción alfabética que explica la escena:

Ynic 8 dias del mes de Enero in Juevestica q[ui]npilloque yeintin ycalpixcauh catca yn alonso lavila no yehuatl in via castilla. Auh ce nepa [n]tla tonatiuh co[n]pilloq[ue] Yquey çan yovaltica yn q[ui]nxexelloque. Auh yn imoztlayoc viernes q[ui]nq[ui]chcotonq[ue] omentin yehuatl barthasal perez yva[n] yteiccauh don p [edr]o. (El 8 del mes de enero, jueves, colgaron a tres mayordomos que pertenecían a Alonso Dávila; también a aquel que iba para Castilla. Y al medio día colgaron al tercero. De noche los despedazaron. Al día siguiente, viernes, degollaron a dos: Baltasar Pérez y su hermano menor don Pedro). (Dibble 1963, p. 79)

Fray Juan de Torquemada (1975, vol. II, libro 5, cap. 20, p. 399) explica con más detalle el asunto y, según su versión, deja entrever que el escribano del Códice Aubin estaba mezclando datos. Explica que don Pedro y don Baltasar de Quesada fueron degollados con don Baltasar de Sotelo por conspirar contra el rey (ibid., cap. 18, p. 389). Entonces se ahorcó también a un tal Oñate, junto con Gonzalo Núñez y Juan de Victoria, estos últimos criados de Alonso Dávila. Ahora bien, según la versión de Chimalpain (2003, p. 295), don Pedro y don Baltasar Quesada Pérez fueron decapitados el 9 de enero y al día siguiente [Baltasar de] Sotelo recibió el mismo destino. Aunque el Manuscrito Mexicain, núm. 217 no menciona ningún nombre, para el año 10 Caña (1567) sí registra la decapitación de tres personas que habían ayudado a Alonso Dávila.

Ahora bien, la presencia de un baúl y dos bolsas podría ser una alusión a los calpixque o mayordomos de Alonso Dávila. O sea a Gonzalo Núñez y Juan de Victoria, los tesoreros que recogían el dinero del tributo y después hacían los correspondientes pagos. En el folio anterior vimos que un soldado estaba asociado a un baúl con monedas, lo que parece sugerir que tal caja era empleada 
para guardar el dinero. La línea que conecta las dos bolsas con la xiuhhuitzolli se podría entonces leer como « calpixque del señor », pero no hay nada que permita confirmar esta lectura. El lugar de caña y el agua no se ha podido identificar.

Tener la sentencia de Alonso Dávila al final del folio 25r y la de sus calpixque al final del folio $25 \mathrm{v}$ nos permite fechar la llegada de las autoridades en este folio entre 1566 y 1568 aproximadamente. En ese tiempo, la venida más importante fue la del virrey don Gastón de Peralta, marqués de Falces, el 21 de octubre de 1566. Al año siguiente, el 31 de octubre de 1567, llegó el licenciado Muñoz para investigar los problemas alrededor de la conspiración de Alonso Dávila, resultado de lo cual fue la condena de sus calpixque. Por otro lado, el 19 de enero de 1568, don Francisco Jiménez, indígena de Tecamachalco, se convertía en juez-gobernador de Tenochtitlan. Más difícil de identificar es el obispo a caballo, pues en ese tiempo ya estaba Alonso de Montúfar en la Nueva España, quien no murió hasta el año de 1572. Tampoco hemos encontrado datos para reconocer al clérigo en la esquina inferior izquierda. Sin glifos onomásticos y un contexto más claro será difícil identificar a estos dos últimos personajes.

\section{Conclusión}

En los anales mexicas suele haber una sección sobre su historia más antigua, relativa a la salida de Aztlan y la fundación de Tenochtitlan, la cual también contempla los sucesos que tuvieron lugar al inicio de la historia de su altepetl. Los anales suelen contener, asimismo, una historia más reciente que se inicia con la llegada de los españoles a estas tierras. Sin embargo, es un hecho que la sección relativa a la Conquista y Colonización no ha recibido la suficiente atención por parte de los etnohistoriadores, más interesados en la historia indígena prehispánica, y especialmente en la historia de la peregrinación mexica. No obstante, lo interesante del registro de los eventos coloniales es que éstos fueron hechos por los mismos indígenas, mostrándonos ellos su propia visión de un periodo que transformó profundamente su vida. Es decir, no sólo representaron los momentos o eventos históricos que ellos consideraron cómo los más importantes, sino que también registraron la manera de cómo los percibieron. Es probable que un español nunca hubiera puesto tanta atención al acto de mutilar las manos de unos músicos en plena fiesta del Toxcatl como ellos lo hicieron. El impacto que este acto les provocó debió haber sido tal, que muchas de las fuentes indígenas lo registraron de manera notable. Un suceso que no sólo plasmaron en el registro pictográfico como el del Códice Azcatitlan, sino también en los textos alfabéticos escritos en nahuatl de otros muchos anales. Esto nos lleva a concluir que se trataba de una historia dirigida a la comunidad indígena hablante de la lengua y no para que fuese leída por los españoles. 
Ahora bien, el razonamiento detrás de la selección de eventos a representar en los anales es un problema complejo. Lo que vemos es que, mientras los discursos en la sección prehispánica suelen ser políticamente dirigidos, como un programa « oficial» del linaje gobernante, en la sección colonial se pierde esa tendencia y se convierte en un simple registro de eventos relevantes por ser llamativos o dramáticos. Este cambio, no obstante, parece estar determinado por la función del tlacuilo o amanuense, que antes de la Conquista era un funcionario del linaje gobernante y en la Colonia pasa a ser una persona autónoma que escribe por su propio interés. Esto implica, en consecuencia, que, si el primero seguía una lógica narrativa, el segundo imponía su propio criterio, pudiendo éste escapar a veces a la comprensión del lector moderno.

Teniendo presente lo anterior, en líneas generales se puede decir que en el Códice Azcatitlan se eligió representar ciertos eventos que fueron organizados según su naturaleza. Del folio $22 \mathrm{v}$ al folio $24 \mathrm{r}$ se mencionaron los acontecimientos que iban desde la llegada de los españoles a la ciudad de México hasta la capitulación de la misma, representados en grandes escenas que cubrían dos páginas. Entre los folios $24 \mathrm{v}$ y $25 \mathrm{v}$ el formato cambió para representar más eventos en escenas más pequeñas, que parecen estar organizadas en dos filas. La superior se destinó a hechos históricos puntuales que eran importantes para la ciudad y su gente como el paso por Hueymollan y la guerra en Culiacan, la construcción del túmulo imperial o la llegada de ciertas autoridades coloniales. La fila inferior se dedicó a eventos relacionados con el « buen gobierno »: la justicia, la elección de gobernantes, la colecta de tributo y el servicio personal.

Esto no quita que en su sección colonial el Códice Azcatitlan no deje de ser un documento complejo. Lo es por tres motivos principalmente. En primer lugar, por la selección de algunos sucesos tan locales que no quedaron registrados en ninguna otra fuente, un aspecto común en los anales. En segundo lugar, por la falta de algún texto o nota alfabética que contribuya a explicar las imágenes. En tercer lugar, por la ausencia de referencias cronológicas, probablemente porque el códice nunca se terminó de pintar. No obstante, a través del cuidadoso trabajo comparativo con otros documentos, alfabéticos o pictográficos, pero sobre todo a través de la comparación con otros anales, vemos que es posible proponer una lectura de su contenido. Un proyecto que esperamos ampliar a todas las secciones coloniales de los anales mexicas. *

* Manuscrit reçu en octobre 2010, accepté pour publication en mars 2012. 


\section{Notas}

1. En este caso uno podría sugerir que la existencia de anales en esta región es debido a la presencia de nahuas procedentes del centro de México (véase Dehouve 1995).

2. Barlow (1949) paginó los folios con el inconveniente de que el documento original no tiene tal paginación y, por tanto, es difícil encontrar la página referida. Graulich (1995), por su parte, prefirió referirse a los folios como láminas, juntando dos páginas en una sola lámina. El problema de su sistema de referencia es que teniendo en cuenta que entre los folios $4 \mathrm{v}$ y $5 \mathrm{r}$ falta un folio, Graulich aunó ambos folios en una sola lámina (lám. V). No obstante, en la parte colonial cada página recibe un número de lámina.

3. El esclavo negro aparece también en la lámina 57 de Durán, andando tras Cortés que va montado en su caballo. Las láminas se encuentran en los folios 207r y 208v de su obra. Para una magnífica reproducción de ésta, véase la página web « Biblioteca Digital Hispánica » de la Biblioteca Nacional de España.

4. Véase, por ejemplo, la foto 15 de la Tira de Tepechpan (1996) o la lámina 77 del Códice Mexicanus (1952).

5. En el Lienzo de Quauhquechollan, por ejemplo, vemos escenas de tamemes, mujeres e incluso esclavos negros. Sobre el tema de esos y otros protagonistas fundamentales para el proceso de conquista consúltese Asselbergs (2004), Matthew y Oudijk (2007) y Oudijk y Restall (2008).

6. Graulich (1995, p. 16) demostró que en el Códice Azcatitlan participaron dos pintores, explicando Castañeda de la Paz (s. d.) que ambos trabajaban en diferentes partes del códice al mismo tiempo, aunque en muchas escenas varios elementos quedaron sin concluir, como es aquí el caso.

7. Narváez venía con la orden dictada por el gobernador de Cuba, Diego Velázquez, de aprehender a Cortés. Las referencias al suceso son numerosas en las fuentes. Véase Anales de Tlatelolco (2004, p. 101), Durán (1995, vol. I, cap. 75, pp. 617-618), Códice Aubin (1963, p. 54), Sahagún (2000, libro XII, cap. 19, p. 1193).

8. En el grupo de las primeras están el Códice Aubin (1963, p. 54) y López de Gómara (1987, pp. 228-229). En el segundo grupo tenemos los Anales de Tlatelolco (2004, p. 101), Durán (1995, vol. I, cap. 75 , p. 620), Sahagún (2000, libro XII, cap. 19, p. 1193).

9. Para Torquemada (1975, vol. II, libro 4, cap. 66, pp. 202-203) el propósito de la fiesta era dar muerte a los conquistadores y sacrificar a los que se pudieran capturar vivos, aunque hay también versiones que dicen que debido a lo ricamente ataviados que iban los señores se despertó la codicia de los españoles.

10. Si no hay una referencia bibliográfica específica en el texto para el Códice Aubin y los Manuscritos Mexicains BnF 40 y 217 debe consultarse Lehmann y Kutscher (1981).

11. Esta observación del personaje con las manos cortadas la hizo Federico Navarrete en el coloquio en torno al Códice Azcatitlan organizado por el Instituto de Investigaciones Antropológicas y el Instituto de Investigaciones Históricas de la UNAM en abril de 2010, a cargo de Ángela Herren, María Castañeda y el propio Navarrete. Medina González (1998, p. 98) tradujo «les cortaron las manos, los hicieron pedazos ", pero el verbo quincotonque hace alusión a las manos y no a los que tocaban el tambor.

12. Se trata de las ondas del agua, tal como se dibujan las de la laguna que rodeaba Aztlan en los folios lv y $2 \mathrm{r}$ de este códice.

13. Véase la descripción de todos estos eventos en Cortés (Tercera Carta, 1992, pp. 130-162), López de Gómara (1987, pp. 285-288) o Díaz del Castillo (1992, cap. 151-156). Véase asimismo Sahagún (2000, libro XII, cap. 30-32, pp. 1211-1216), Torquemada (1975, vol. II, libro 4, cap. 89, pp. 268-270) y Durán (1995, vol. I, cap. 77, pp. 635-644). La mayoría de las fuentes señalan que se trataba de trece bergantines.

14. Para una imagen de una acequia con indígenas, españoles e incluso caballos ahogados véase el folio 45r del libro XII del Códice Florentino.

15. El cronista habla también de la existencia de una acequia atajada con una albarrada o pared, algo más al norte de la iglesia de San Antonio. Otra albarrada estaba en el sitio de Huitzillan, cerca de la 
iglesia de San Pablo, cabecera de una de las parcialidad de Tenochtitlan (Sahagún 2000, libro XII, cap. 30, pp. 1211-1212).

16. Tal organización fue sugerida por Ángela Herren en el coloquio en torno al Códice Azcatitlan ya citado (véase nota 11). En relación a este asunto es importante notar que en las tres secciones del Códice Azcatitlan hay claras evidencias de que ciertas escenas no se terminaron. En lo que a la tercera sección respecta, hay varios ejemplos entre los cuales citamos algunos que sirvan como referencia: al guerrero que está en la parte superior del folio 23r le falta su macahuitl, del que sólo se llegó a pintar la empuñadura; en los folios $23 \mathrm{v}$ y $24 \mathrm{r}$ nunca se llegó a pintar el agua del entorno en el que tenían lugar las batallas; en el folio $24 \mathrm{v}$ tampoco se terminó de pintar el sacerdote que está bautizando, al que le faltan sus piernas. Lo mismo sucedió con los cuatro gobernantes que están sendentes en sus tronos, a quienes les faltan sus nombres o bien los glifos toponímicos de los lugares donde gobernaban. El círculo del que salía un camino hacia Hueymollan es obvio que tampoco se concluyó.

17. Decía Torquemada (1975, vol. I, libro 3, cap. 41, p. 454) que Hibueras era el nombre de Honduras, mientras que el autor anónimo de la Historia de los mexicanos... (1979, p. 65) señalaba que su nombre era Guaimula [sic: Huey Mollan].

18. Cortés jamás dijo que mandara ahorcar a Tlacotzin y a Oquitzin. Sí murieron en el camino de vuelta de las Hibueras, pero probablemente por enfermedad. No obstante, y por orden de Cortés, Tlacotzin fue nombrado gobernador de los tenochcas tras la muerte de Cuauhtemoc. Véase Chimalpain (2003, pp. 214-217), Tezozomoc (1992, p. 166) y Procesos de indios... (2002, p. 116).

19. Como se ha visto en la nota 18 , el sucesor de Cuauhtemoc fue Tlacotzin. Sin embargo, debido a que éste murió en el camino de vuelta de las Hibueras y nunca llegó a sentarse en el trono tenochca, muchas fuentes lo ignoran y simplemente mencionan a Motelchiuhtzin como el sucesor de Cuauhtemoc. Los españoles rápidamente designaron a Tlacotzin y Motelchiuhtzin con el título de gobernadores, sin embargo los textos indígenas los denominaron quauhtlatoani (« señor-águila »), debido a que no los consideraban sus señores legítimos. Para Lockhart (1992, p. 33), el quauhtlatoani era un gobernador interino que ostentaba el poder « hasta que se pudiera acordar el nombramiento de un heredero dinástico o éste fuera mayor de edad ».

20. Graulich (1995, p. 146, nota 97) concluyó que debía tratarse de los cuatro señores de Tlaxcala, sin aportar argumentos para tal interpretación (véase nota 21). Para dos escenas similares consúltense los folios 14 y 16 del Códice Azoyú 2.

21. Suponemos que Graulich interpretó el círculo como la tortilla (tlaxcalli) que da nombre a Tlaxcala y, por ende, dedujo que el cerro del molcajete con un ave en su interior era un lugar próximo a esa localidad, llamado Totolapan o Totolac (Graulich, 1995, p. 146, nota 97). Esta lectura es la que probablemente también lo llevó a concluir que los cuatro señores bajo esos topónimos eran tlaxcaltecas (véase nota 20). El problema con esta interpretación es que no se tuvieron presentes dos factores: ni el momento histórico en el que se representó la escena en relación a las demás en el documento (la secuencia de eventos) ni los contextos similares en otros anales, donde claramente se representa la muerte de Cuauhtemoc en Hueymollan. No está de más añadir que la representación de lugares y personajes tlaxcaltecas no concuerda con el enfoque del relato del Códice Azcatitlan, con énfasis en la historia tenochca y tlatelolca.

22. Teoyotl se podría traducir como « dios-idad », referiéndose al inicio del tiempo del dios cristiano.

23. Véase asimismo Graulich (1995, p. 144, nota 94), y Doesburg (2001, pp. 171-175) para una discusión sobre el palo volador y su uso en tiempos prehispánicos.

24. Barlow (1995, p. 144) señaló erróneamente que se trataba del Culhuacan, al pie del cerro de la Estrella, en la cuenca de México. Para una discusión sobre Nuño de Guzmán y la conquista de la Nueva Galicia véase Marín Tamayo (1992). Sobre los métodos de reclutamiento y la participación indígena en la conquista véase Altman (2007).

25. Es decir, los dos están muertos. Por ello no estamos de acuerdo con la interpretación de Barlow (1995, pp. 144, 146) cuando dice que tras la muerte de Ehecatl de Culhuacan, éste fue sucedido por «Ojo de Agua ». 
26. Generalmente « Andrés » se suele representar mediante la cruz de San Andrés (Galarza 1996, p. 54). No obstante, lo que observamos en esta sección del documento es que su pintor parece estar experimentando con la expresión fonética de los nombres onomásticos y toponímicos. Véase el siguiente folio 25r para el caso de « Esteban » y « Tlaxcala ».

27. Barlow (1995, p. 148) reconoció la dificultad de interpretar esta escena por falta de referencia en las fuentes españolas. No obstante, concluyó que el tambor era un instrumento propiedad de la iglesia y que el funcionario estaba relacionado con su adquisición. Respecto a los otros elementos, dedujo que el círculo era el glifo de Tlaxcala, representado a través de una tortilla (tlaxcalli), a veces acompañada de dos manos que la están amasando, como también se observa en la lámina 57 de Durán (1995, vol. I). No obstante, el dibujo también se presta a otra posible lectura: la de tocar el tambor. En cuanto al glifo del agua, no hay tampoco evidencias que sea un barrio de Tlaxcala como sostenía este investigador.

28. Generalmente se pinta un círculo moteado para ceniza (¿?) (nex-tli) y una bandera (pan-tli) para decir Ixtepan o Esteban (ff. 49r y 52r del Códice Aubin). En este caso se utilizó una piedra (te-tl), una bandera (pan-tli) para (Es)tepan, pero no hemos podido identificar el primer elemento que compone la primera parte de su nombre. La flor (xoch-itl) sobre la sementera ( $m i l-l i)$ proporcionaría el nombre de Xochimilco. Normalmente el glifo de Tlaxcala es una tortilla (tlaxcal-li), como se ve más adelante en esta misma escena. Sin embargo, el pintor parece haber intentado dibujar un complejo acercamiento fonético cuando representó un molcajete (cax-itl) y una casa (cal-li) con agua ( $a$ - $t l)$. Agradecemos a Sebastián van Doesburg esta última lectura.

29. El propio Códice Aubin, pero también Chimalpain (2003, p. 269), explican que don Esteban fue a Tenochtitlan en calidad de juez para interrogar a don Diego por los abusos cometidos durante su gobierno. Sin embargo, éste murió poco antes de llegar el juez, como parece indicar la escena en el Azcatitlan. El virrey decidió entonces que se quedase en calidad de juez-gobernador hasta que fuera elegido un nuevo gobernante para los tenochcas. Otras referencias en Tezozomoc (1992, p. 175).

30. Pero hay varias cosas más que señalar: bajo la glosa que dice don Esteban se borró otra que decía Cecetzin, nombre indígena de don Cristóbal; la muerte de Tehuetzquititzin y la llegada del juez no se representó en 1554 sino en 1556; por último, comentar que la elección de don Cristóbal Cecetzin fue en 1557 y no en 1556 .

31. Agradecemos a uno de los dictaminadores anónimos del Journal de la Société des Américanistes la referencia de Cervantes de Salazar, la cual ha mejorado considerablemente nuestra identificación de la escena.

32. Torquemada (1975, vol. II, libro 5, cap. 18), Orozco y Berra (1853) y Anales de Juan Bautista (2001, párrs. 30-31).

33. No obstante, Barlow (1995, p. 150) y Graulich (1995, p. 150, nota 98) creyeron ver en la muerte de Carlos V y el enjuiciamiento de los hermanos Dávila el robo del sacramento de una iglesia y el castigo al criminal, cortándole la cabeza. Al soldado español lo interpretaron como el que acusa del robo de la caja fuerte bajo sus pies, dando a entender que el sentenciado también pudo tener relación con este robo.

34. Dos de los dictaminadores de este artículo sugirieron que este personaje podría ser una mujer por su cabello largo y su modo de sentarse en el caballo. Aunque reconocemos que la representación de este personaje es controvertida, creemos que lo que pudiera parecer su cabello es un velo que se recoje a la cintura y que en el Lienzo de Tlaxcala se ata al cuello. Por otro lado, también nos resulta raro que una mujer en la Nueva España, y en el siglo XVI, vistiera pantalones y portara sombrero.

\section{REFERENCIAS CITADAS}

\section{Altman Ida}

2007 "Conquest, coercion, and collaboration: Indian allies and the campaigns in Nueva Galicia », in Laura Matthew y Michel R. Oudijk (eds), Indian 
Conquistadors. Indigenous allies in the Conquest of Mesoamerica, University of Oklahoma Press, Norman, pp. 145-174.

Anales de Juan Bautista

2001 ¿Cómo te confundes? ¿Acaso no somos conquistados? Anales de Juan Bautista, paleografía, traducción y estudio de Luis Reyes García, Biblioteca Lorenzo Boturini, Insigne y Nacional Basílica de Guadalupe/CIESAS, México.

Anales de Tlatelolco

2004 Anales de Tlatelolco, paleografía y traducción de Rafael Tena, Cien de México, México.

AsSELBERGS Florine

2004 The Lienzo de Quauhquechollan: a Nahua vision of the conquest of Guatemala, CNWS Research School, Leiden.

BARLOW Robert $\mathrm{H}$.

1949 "El Códice Azcatitlan », Journal de la Société des Américanistes, 38, pp. 101-135.

1989 «Una pintura de la conquista en el templo de Santiago », in Jesús Monjarás-Ruiz, Elena Limón y María de la Cruz Paillés H. (eds.), Tlatelolco, fuentes e historia. Obras de Robert H. Barlow, vol. 2, Instituto Nacional de Antropología e Historia/Universidad de las Américas, México/Cholula, pp. 211-216 [originalmente publicado en Memorias de la Academia Mexicana de la Historia, vol. 4, 1945, pp. 490-497].

1995 «Comentario », in Codex Azcatitlan/Códice Azcatitlan, re-edición del comentario de 1949 con introducción y notas de Michel Graulich, Bibliothèque nationale de France/Société des Américanistes, París.

BARLow Robert H. y Byron McAFEE

1989 «Unos anales coloniales de Tlatelolco, 1519-1633 », in Jesús MonjarásRuiz, Elena Limón y María de la Cruz Paillés H. (eds.), Tlatelolco. fuentes e historia. Obras de Robert H. Barlow, vol. 2, Instituto Nacional de Antropología e Historia/Universidad de las Américas, México/Cholula, pp. 217-254 [originalmente publicado en Memorias de la Academia Mexicana de la Historia, vol. 7, 1948, pp. 152-187].

Boone Elizabeth Hill

2000 Stories in red and black. Pictorial histories of the Aztec and Mixtecs, University of Texas Press, Austin.

Castañeda de la Paz María

1997 «Los códices históricos mexicas. El Códice Azcatitlan », Estudios de Historia Social y Económica de América, 14, pp. 273-299.

1999 «Los tlatelolcas y su ascendencia tepaneca en las fuentes mexicas », Expresión Antropológica, 8-9, pp. 38-53.

2005 «El Códice X o los anales del "Grupo de la Tira de la Peregrinación”. Copias, duplicaciones y su uso por parte de los cronistas », Tlalocan, 15, pp. 183-214. 
2009a «Codex Azcatitlan and the work of Torquemada. A historiographic puzzle in the Aztec-Mexica sources ", Latin American Indian Literatures Journal, 24 (2), pp. 151-194.

2009b «Filología del corpus pintado (siglos XVI-XVIII): códices, techialoyan, pinturas y escudos de armas ", Anales del Museo de América, 17, pp. 78-90.

s. d. «El Códice Azcatitlan », in Xavier Noguez y Raymundo Martínez (eds.), Códices y documentos de tradición indígena del Estado de México, El Colegio Mexiquense, Zinacantepec.

Cervantes de Salazar Francisco

1972 México en 1554 y túmulo imperial, Editorial Porrúa, col. «Sepan cuantos... » 25, México.

Chimalpain Cuauhtlehuanitzin

2003 Séptima relación de las Différentes histoires originales, paleografía y traducción de Josefina García Quintana, Universidad Nacional Autónoma de México, Instituto de Investigaciones Históricas, México.

Códice Aubin

1963 véase Dibble.

1981 «Geschichte der Azteken, 1168-1607 (Codex Aubin) 》 in Geschichte der Azteken. Codex Aubin und verwandte Dokumente, traducción y comentarios de Walter Lehmann y Gerdt Kutscher, Gebr. Mann Verlag, Berlín, pp. 1-61, 213-294.

Códice Azcatitlan

1995 Codex Azcatitlan/Códice Azcatitlan, introducción y notas de Michel Graulich y comentario de Robert H. Barlow, Bibliothèque nationale de France/Société des Américanistes, París.

Códice Azoyú 2

2012 Códice Azoyú 2. El señorío de Tlapa-Tlachinollan, comentarios de Constanza Vega Sosa y Michel R. Oudijk, Fondo de Cultura Económica, México.

Códice en Cruz

1981 edición facsimilar con comentario de Charles E. Dibble, 2 vols., University of Utah Press, Salt Lake City.

Códice Florentino

1979 edición facsimilar del manuscrito 218-20 de la colección Palatina de la Biblioteca Medicea Laurenziana, 3 vols., Gobierno de la República, México.

Códice Mexicanus

1952 "Commentaire du Codex Mexicanus», por Ernst Mengin, Journal de la Société des Américanistes, 41 (2), pp. 387-498.

Códice Telleriano-Remensis

1995 Codex Telleriano-Remensis. Ritual, divination, and history in a pictorial Aztec manuscript, comentario de Eloise Quiñones Keber, University of Texas Press, Austin. 
Códice de Tlatelolco

1980 por Robert H. Barlow, Anales de Tlatelolco. Unos anales históricos de la nación mexicana y Códice de Tlatelolco, ediciones Rafael Porrúa, México, pp. 105-143.

1994 estudio preliminar de Perla Valle, Códices Mesoamericanos 1, Instituto Nacional de Antropología e Historia/Benemérita Universidad Autónoma de Puebla, México.

Códice Vaticano A

1996 Religión, costumbres e historia de los antiguos mexicanos. Libro explicativo del llamado Códice Vaticano A, introducción y explicación Ferdinand Anders y Maarten Jansen, Akademische Druck- und Verlagsanstalt/Fondo de Cultura Económica, México.

CORTÉs Hernán

1992 Cartas de Relación, nota preliminar de Manuel Alcalá, Editorial Porrúa, México.

Crónica Mexicayotl

1992 véase Tezozomoc.

Dehouve Danièle

1995 Hacia una historia del espacio en la montaña de Guerrero, Centro de Estudios Mexicanos y Centroamericanos/Centro de Investigaciones y Estudios Superiores en Antropología Social, México.

Díaz del Castillo Bernal

1992 Historia de la Conquista de Nueva España, introducción y notas de Joaquín Ramírez Cabañas, Editorial Porrúa, México.

DiBBLE Charles

1963 Historia de la nación mexicana: Reproducción a todo color del Códice de 1576 (Códice Aubin), Ediciones José Porrúa Turanzas, Madrid.

1981 véase Códice en Cruz.

DoESBURG Sebastian van

2001 Códices cuicatecos: Porfirio Díaz y Fernández Leal, Gobierno Constitucional del Estado de Oaxaca/Miguel Ángel Porrúa, México.

DURÁn fray Diego

1995 Historia de las Indias de Nueva España e Islas de tierra firme, 2 vols., Cien de México, México.

GaLARZa Joaquín

1996 Estudios de escritura indígena tradicional azteca-nahuatl, Archivo General de la Nación/CEMCA, México.

Graulich Michel

1995 véase Códice Azcatitlan.

Grupo Ixhuatepec

2004 Los códices de Ixhuatepec. Un testimonio pictográfico de dos siglos de conflicto agrario, CIESAS/Colegio de San Ignacio de Loyola Vizcaínas, México. 
Historia de los mexicanos por sus pinturas

1979 Historia de los mexicanos por sus pinturas. Teogonía e historia de los mexicanos por sus pinturas, editado por Angel María Garibay, Editorial Porrúa, México.

JANSEN Maarten

1986 Huisi Tacu. Estudio interpretativo de un libro antiguo: Codex Vindobonensis Mexicanus I, CEDLA, Amsterdam.

1988 « The art of writing in Ancient Mexico: an ethno-iconological perspective », Visible Religion. Annual for Religious Iconography, 6, pp. 86-113.

LEHMANN Walter y Gerdt KuTSCHER

1981 Geschichte der Azteken: Codex Aubin und verwandte Dokumente, Gebr. Mann Verlag, Berlín.

Lienzo de Tlaxcala

1981 véase Muñoz Camargo.

LOCKHART James

1992 The Nahuas after the Conquest. A social and cultural history of the Indians of Central Mexico, sixteenth through eighteenth centuries, Stanford University Press, Stanford.

1993 We people here: Nahuatl accounts of the Conquest of Mexico, edición y traducción de James Lockhart, Wipf and Stock publishers, Eugene.

Loo Peter van

1986 Códices, costumbres y continuidad. Un estudio de la religión mesoamericana, Leiden University, col. « Indiaanse Studies » 2, Leiden.

LÓPEZ DE Gómara Francisco

1987 La conquista de México, edición de José Luis de Rojas, col. « Historia » 16/ «Crónicas de América » 36, Madrid.

Manuscrito Mexicain núm. 40

1981 véase Lehmann y Kutscher, pp. 109-136, 321-354.

Manuscrito Mexicain núm. 217

1981 véase Lehmann y Kutscher, pp. 61-91, 295-308.

MARín TAMAYo Fausto

1992 Nuño de Guzmán, Siglo xxi/Difocur/Sinaloa, México.

MatTHEw Laura y Michel R. OudiJK (eds.)

2007 Indian Conquistadors. Indigenous allies in the Conquest of Mesoamerica, University of Oklahoma Press, Norman.

Medina GonZÁlez Xóchitl

1998 Histoire mexicaine depuis 1221 jusqu'en 1594. Manuscrito núm. 40 del fondo de Manuscritos mexicanos, Bibliothèque nationale de France/Instituto Nacional de Antropología e Historia, México.

Muñoz Camargo Diego

1981 Descripción de la ciudad y provincia de Tlaxcala, edición facsimilar del manuscrito Glasgow con un estudio preliminar de René Acuña, Instituto de Investigaciones Filológicas/Universidad Nacional Autónoma de México, México. 
NAVARRETe Federico

2000 «The path from Aztlan to Mexico. On visual narration in Mesoamerican codices », Res. Anthropology and Aesthetics, 37, pp. 31-48.

2004 "The hidden codes of the Codex Azcatitlan", Res. Anthropology and Aesthetics, 45, pp. 144-160.

OrozCo y BerRa Manuel

$1853 \quad$ Noticia histórica de la conjuración del marqués del Valle. Años de 1565-1568, tipografía de R. Rafael, México.

OUDIJK Michel R.

2000 Historiography of the Bènizàa. The postclassic and early colonial periods (1000-1600 AD), Research School CNWS, Leiden.

2008 «De tradiciones y métodos: investigaciones pictográficas », Desacatos, 27, pp. 123-138.

OudiJK Michel y Matthew Restall

2008 La conquista indígena de Mesoamérica. El caso de don Gonzalo Mazatzin Moctezuma, Secretaría de Cultura del Estado de Puebla/Universidad de las Américas/Instituto Nacional de Antropología e Historia, Puebla.

Pérez Zevallos Juan Manuel

2003 Xochimilco ayer I, Gobierno del Distrito Federal/Delegación Xochimilco/ Instituto Mora, México.

Procesos de indios

2002 Procesos de indios idólatras y hechiceros, Archivo General de la Nación, México [1912].

SAHAGÚN Fray Bernardino de

2000 Historia General de las cosas de la Nueva España, 3 vols., estudio introductorio, paleografía, glosario y notas de Alfredo López Austin y Josefina García Quintana, Cien de México, México.

Tezozomoc Fernando Alvarado

1992 Crónica Mexicayotl, Universidad Nacional Autónoma de México/Instituto de Investigaciones Históricas, México.

Tira de Tepechpan

1996 Tira de Tepechpan: códice colonial procedente del Valle de México, 2 vols, comentario de Xavier Noguez, Instituto Mexiquense de Cultura, Toluca.

TORQuemada Fray Juan de

1975 Monarquía indiana, 7 vols., Universidad Nacional Autónoma de México/Instituto de Investigaciones Históricas, México. 